\title{
Reducing Global Environmental Uncertainties in Reports of Tropical Forest Carbon Fluxes to REDD+ and the Paris Agreement Global Stocktake
}

\author{
Alan Grainger ${ }^{1, *}$ and Junwoo Kim ${ }^{1,2}$ \\ 1 School of Geography, University of Leeds, Leeds LS2 9JT, UK; darkcroa@snu.ac.kr \\ 2 School of Earth and Environmental Sciences, Seoul National University, Seoul 08826, Korea \\ * Correspondence: a.grainger@leeds.ac.uk
}

Received: 22 May 2020; Accepted: 13 July 2020; Published: 23 July 2020

\begin{abstract}
The magnitude of net carbon dioxide emissions resulting from global forest carbon change, and hence the contribution of forests to global climate change, is highly uncertain, owing to the lack of direct measurement by Earth observation and ground data collection. This paper uses a new method to evaluate this uncertainty with greater precision than before. Sources of uncertainty are divided into conceptualization and measurement categories and distributed between the spatial, vertical and temporal dimensions of Earth observation. The method is applied to Forest Reference Emission Level (FREL) reports and National Greenhouse Gas Inventories (NGGIs) submitted to the UN Framework Convention on Climate Change (UNFCCC) by 12 countries containing half of tropical forest area. The two sets of estimates are typical of those to be submitted to the Reducing Emissions from Deforestation and Degradation (REDD+) mechanism of the UNFCCC and the 2023 Global Stocktake of its Paris Agreement, respectively. Assembling the Uncertainty Fingerprint of each estimate shows that Uncertainty Scores are between 10 and 14 for the NGGIs and 5 and 10 for the FREL reports, and so both exceed the threshold of 2 when it is advisable to evaluate uncertainty by standard statistical methods. Conceptualization uncertainties account for $60 \%$ of all uncertainties in the NGGIs and $47 \%$ in the FREL reports, e.g., there is incomplete coverage of forest carbon fluxes, and limited disaggregation of fluxes between different ecosystem types and forest carbon pools. Of the measurement uncertainties, all FREL reports base forest area estimates on at least medium resolution satellite data, compared with only 3 NGGIs; after REDD+ Readiness schemes, mean area mapping frequency has fallen to 2.3 years in Latin America and 3.0 years in Asia, but only 8.3 years in Africa; and carbon density estimates are based on national forest inventory data in all FREL reports but only 4 NGGIs. The effectiveness of the Global Stocktake and REDD+ monitoring will therefore be constrained by considerable uncertainties, and to reduce these requires a new phase of REDD+ Readiness to ensure more frequent national forest inventories and forest carbon mapping.
\end{abstract}

Keywords: tropical forest carbon change; theory of Earth observation science; global environmental uncertainties; climate change; Paris Agreement

\section{Introduction}

How uncertain is information on global environmental change phenomena derived wholly or partly from very large numbers of satellite images? This is one of the challenges that will face the UN Framework Convention on Climate Change (UNFCCC) when in 2023 it holds the first Global Stocktake, to monitor implementation of its Paris Agreement to reduce carbon dioxide $\left(\mathrm{CO}_{2}\right)$ emissions that contribute to global climate change and keep the rise in mean global temperature "to well below $2{ }^{\circ} \mathrm{C}$ above pre-industrial levels" [1]. It also affects how the UNFCCC monitors progress in 
reducing emissions linked to forest carbon change under its Reducing Emissions from Deforestation and Degradation (REDD+) mechanism [2]. After emissions of $\mathrm{CO}_{2}$ following deforestation and forest degradation (in the tropics especially) are offset by uptake in afforestation, reforestation, regrowth, and enhanced growth in existing forests, net forest emissions could account for $11 \%$ of all $\mathrm{CO}_{2}$ emissions [3]. Yet the global magnitudes of these forest carbon fluxes are highly uncertain [4]. This paper demonstrates a new approach to evaluating the uncertainties associated with estimates of the rates of global and national forest carbon change.

Evaluating these uncertainties is difficult for four reasons. First, lack of direct planetary measurement. Operational global scientific monitoring of terrestrial change using remote sensing satellites is still in its early stages [5], e.g., the first 'wall-to-wall' global forest area map based on Landsat images was not published until 2012 [6]. Monitoring global changes in forest carbon stocks using remote sensing data and ground data, e.g., [7], is even less advanced, and more challenging since it involves two attributes of forests, i.e., their area and carbon density. While satellite data have been used to survey national forest area in some tropical countries since the 1970s [8,9], such surveys have been infrequent elsewhere until recently [10]. National forest carbon monitoring capacity is even more limited in scope, and there is concern that uncertainty about the sizes of national forest carbon fluxes will hinder REDD+ monitoring [11,12]. Various REDD+ Readiness programmes have been implemented to strengthen capacity so that developing countries can establish the Measurement, Reporting and Verification (MRV) centres needed to participate in REDD+ [13]. These programmes have led to more frequent forest area surveys in some countries, but progress generally has been mixed [14], especially in measuring forest carbon fluxes.

A second difficulty is that, owing to the limited information obtained by processing satellite data, estimates of global and national rates of forest carbon change often use information from other sources. Consequently, many estimates are hybrids of information derived from remote sensing measurements and ground measurements, and governmental or intergovernmental statistics and other published sources which may be only loosely linked to measurements [4]. Estimates are also qualitatively structured, e.g., by different intergovernmental reporting guidelines and scientific classification systems. As these estimates are therefore likely to be heavily influenced by qualitative constraints, conventional quantitative calculations of their uncertainties may be misleading [15]. A full uncertainty assessment requires a method suited to hybrid information.

The third complication arises from imperfect conversion of satellite data into usable information. The Copernicus Programme vision of a seamless chain from Earth observation data to usable information in the hands of decision-makers [16] is seldom achieved in practice by the "Earth observation system" responsible for each chain [17]. Early maps of tropical forest area change were very uncertain since instead of wall-to-wall surveys with medium-resolution optical images [18], sensor resolution was traded off to ensure completeness of areal coverage and cut image and processing costs [4]. More complex trade-offs may occur with the dual attribute phenomenon of forest carbon change between: (a) sensor resolution; (b) completeness of coverage of forest carbon fluxes (linked to deforestation, forest degradation, reforestation, afforestation and (re)growth); and (c) three forms of disaggregation: (i) the number of carbon pools involved in each flux; (ii) the number of forest ecosystem types with distinct carbon densities that are found in each country; and (iii) the number of land covers, also varying in carbon density, that replace forest after clearance.

A final constraint is that scientific study of planetary measurement is still embryonic. Remote sensing science has paid more attention to analysing single satellite images to assess the precision of specific sensors [19] than to converting the planetary data in very large numbers of images into planetary information and evaluating the uncertainty associated with this. For example, more than 5000 Landsat images are needed for a wall-to-wall map of global forest area (Figure 1). So it is vital to develop generic conceptual methods in the emerging Earth observation science [17] for constructing reliable information on multiple attribute global environmental change phenomena derived from Earth observation data. This paper contributes to these methods by proposing that if Earth observation science 
integrates sensor features and Earth surface features [17] then global environmental uncertainties can be analysed in relation to a norm of direct planetary measurement, which perfectly matches the resolutions of the spatial, vertical and temporal dimensions of Earth observation and the three corresponding dimensions of variation in Earth surface features.

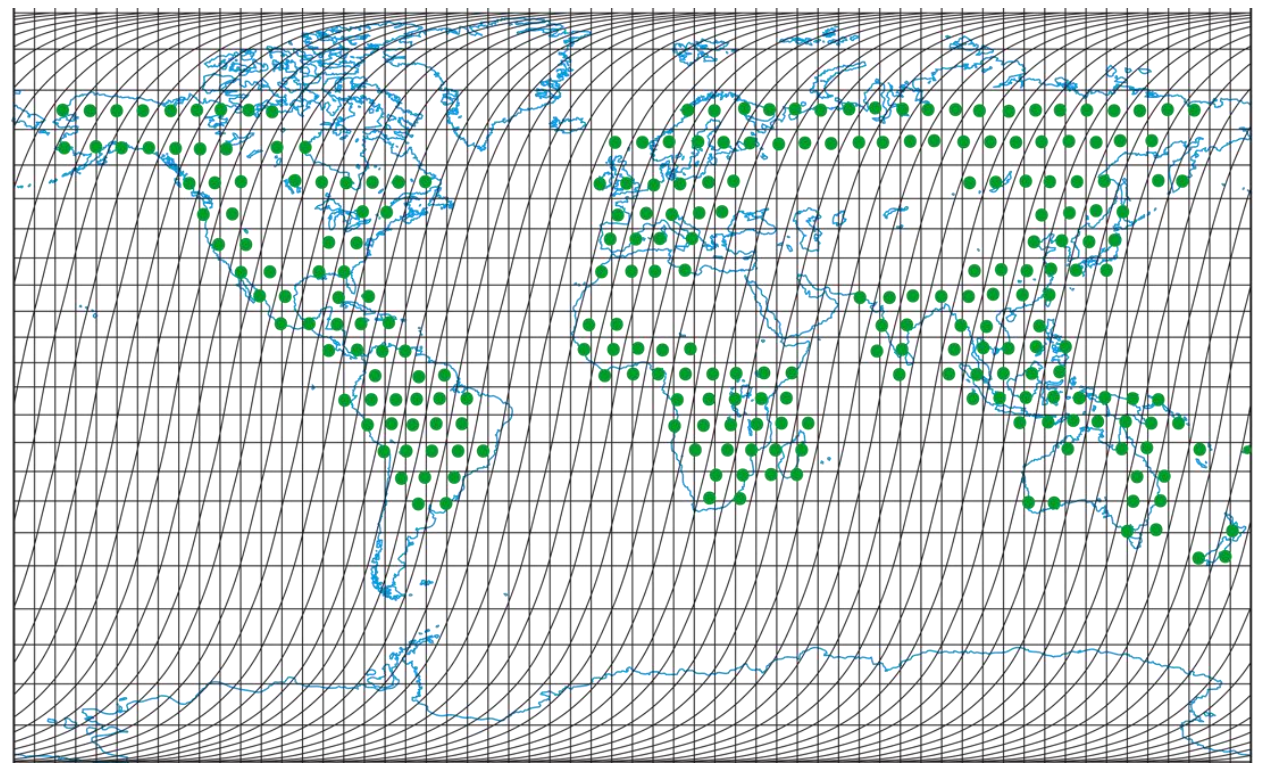

Figure 1. The distribution of global forest area and the path-row matrix of Landsat satellite images.

To fill the methodological gaps highlighted above, this paper extends the Uncertainty Assessment Framework (UAF), devised to evaluate sources of uncertainty associated with estimates of global environmental change phenomena [20]. The UAF divides sources of uncertainty into: (a) a conceptualization category, which includes qualitative uncertainties, such as those linked to completeness and disaggregation; and (b) a measurement category, which includes quantitative uncertainties, such as random errors and systematic errors linked to inadequate sensor resolution etc. Using direct planetary measurement by Earth observation as a norm, the extended UAF further divides these uncertainties between the spatial, vertical and temporal dimensions of Earth observation. The uncertainties associated with any estimate can be coded and combined to construct its Uncertainty Fingerprint, and the fingerprints of different estimates compared visually and by quantitative metrics.

The paper has five sections. The first outlines background material. The second reviews relevant literature. The third describes the extended Uncertainty Assessment Framework and the methods used to apply it here. The fourth evaluates uncertainties associated with estimates in samples of National Greenhouse Gas Inventories, of the kind to be submitted to the Global Stocktake, and of Forest Reference Emission Level reports, which should resemble progress reports to REDD+. These estimates have been recently submitted to the UNFCCC by twelve developing countries containing half of tropical forest area, and from the uncertainties may be inferred the quality of national MRV centres (or Earth observation systems). The fifth discusses the implications of this analysis for reducing uncertainty in reports to the UNFCCC.

\section{Background}

This section outlines information needed to interpret the completeness and disaggregation of national reports to the UN Framework Convention on Climate Change. 


\subsection{Definitions}

The UN Food and Agriculture Organization (FAO) defines forest as "land spanning more than 0.5 hectares (ha) with trees higher than $5 \mathrm{~m}$ and a canopy cover of more than $10 \%$, or trees able to reach these thresholds. It does not include land that is predominantly under agricultural or urban land use" [21].

Deforestation is defined by FAO [22] as "the clearcutting of forests for use other than forestry (principally agriculture)." Vegetation degradation is "a temporary or permanent reduction in the density, structure, species composition or productivity of vegetation cover" [23], and so has spatial, vertical and temporal dimensions. Deforestation is reversed by (a) afforestation, in which forest plantations are established on land not forested in living memory or within 50 years; and (b) reforestation, in which tree cover increases: (i) in existing forested areas, either naturally, or artificially by planting selected timber tree species in forests; and (ii) in previously forested areas abandoned by farmers [24]. The term "forestation" refers to afforestation and reforestation collectively [25]. Forest degradation is reversed by natural forest regrowth, and offset by enhanced growth in existing forest resulting from carbon fertilization and other processes linked to global climate change [26].

Forest carbon change involves changes in forest carbon stocks caused by fluxes linked to these various forest area and biomass changes. The fluxes lead to either emissions of carbon dioxide $\left(\mathrm{CO}_{2}\right)$ into the atmosphere or $\mathrm{CO}_{2}$ removals from the atmosphere.

\subsection{UN Framework Convention on Climate Change}

Every four years the Parties to the UN Framework Convention on Climate Change (UNFCCC) are expected to submit National Communications that report on their implementation of the Convention and include National Greenhouse Gas Inventories [27].

Article 14 of the Paris Agreement requires the UNFCCC to hold a Global Stocktake every five years to evaluate "collective progress towards achieving the purpose of this agreement and its long-term goals" [1]. The first of these goals is to keep the rise in mean global temperature to "well below $2{ }^{\circ} \mathrm{C}$ above pre-industrial levels" and try to limit this rise to $1.5^{\circ} \mathrm{C}$. The first Global Stocktake, in 2023, will synthesize government reports of greenhouse gas emissions and removals and will also consider reports from the Intergovernmental Panel on Climate Change (IPCC) [28].

The majority of $\mathrm{CO}_{2}$ is emitted by burning fossil fuels [29], but net forest emissions could account for $11 \%$ of the total [3] so reducing them can help to mitigate climate change [30,31]. The UNFCCC's "Bali Roadmap" of 2007 included a mechanism for "Reducing Emissions from Deforestation and Degradation with sustainable management of forests, conservation of forest carbon stocks and enhancement of forest carbon stocks" in developing countries. This was called "REDD+" [2,32] to distinguish it from an earlier proposal [33].

Since developing countries could receive up to $\$ 20$ billion a year in compensation for reducing their forest emissions the UNFCCC [32] recognized that any reported reductions should be "measurable, reportable and verifiable". Consequently, a Measurement, Reporting and Verification (MRV) centre should be established in each country [13]. REDD+ Readiness schemes have been implemented with support from international and national agencies to raise existing national forest monitoring capacities to meet MRV requirements [14].

Developing countries wishing to participate in REDD+ should submit to the UNFCCC baseline trends in emissions from which to measure such reductions in a "Forest Reference Emission Level/Forest Reference Level" document. The need to "establish forest reference emission levels and forest reference levels" was recognized by the UNFCCC in 2009 [34] but the terms have not been formally defined subsequently. Informal interpretations have arisen, in which "Forest Reference Emission Level" (FREL) refers to gross emissions over a reference period, and "Forest Reference Level" to net emissions after deducting carbon removals from the atmosphere. For convenience, this paper uses the generic term "Forest Reference Emission Level" and acronym "FREL" to refer to both types of reports. 


\subsection{Disaggregation and Ecosystem Classification Systems}

Estimates of the spatial distribution of tropical forest carbon fluxes would ideally be based on empirical data, collected by measurements stratified by different types of forest ecosystems, as these play a key role in determining the parameters used to convert measurements of timber volume into estimates of biomass density and carbon density [4]. The degree of ecosystem disaggregation of estimates of global and national carbon fluxes can be evaluated by referring to classifications of how major types of ecosystems, or biome types, would ideally be distributed on Planet Earth without human intervention.

The sizes of flux estimates are influenced by which classification system is used. In the early system of Whittaker [35], tropical forest potentially covered at least 2,450 million ha in two main biome types - "tropical rain forest" and "tropical seasonal forest" — which had mean above-ground carbon densities of 212 and 163 tonnes of carbon per ha ( $\mathrm{tC} \mathrm{ha}^{-1}$ ), respectively (Table 1) [36]. Much tropical dry forest may have been included in the 1500 million ha of "savanna", which has mixtures of trees and grasslands at varying densities and a mean carbon density of just $19 \mathrm{tC} \mathrm{ha}^{-1}$. Major global ecosystems are often called biomes, but Whittaker reserved this term for regional variations of global "biome types" [35].

Table 1. The areas, carbon stocks and mean carbon densities of major biome types [35,36].

\begin{tabular}{lrrr}
\hline & Area & Carbon Stock & Carbon Density \\
\hline & $10^{6}$ ha & $10^{3}$ Mt C & $\mathrm{t} \mathrm{C} \mathrm{ha}^{-1}$ \\
\hline Tropical rain forest & 1700 & 359.6 & 211.50 \\
Tropical seasonal forest & 750 & 122.2 & 162.93 \\
Temperate evergreen forest & 500 & 82.3 & 164.50 \\
Temperate deciduous forest & 700 & 98.7 & 141.00 \\
Boreal forest & 1200 & 112.8 & 94.00 \\
Woodland and shrubland & 800 & 22.6 & 28.20 \\
Savanna & 1500 & 28.2 & 18.80 \\
Temperate grassland & 900 & 6.6 & 7.31 \\
Tundra and alpine & 800 & 2.4 & 2.94 \\
Desert scrub & 1800 & 6.1 & 3.39 \\
Extreme desert & 2400 & 0.2 & 0.10 \\
Cultivated land & 1400 & 6.6 & 4.70 \\
Swamp and marsh & 200 & 14.1 & 70.50 \\
Lake and stream & 250 & 0.0 & 0.09 \\
Total continental & $\mathbf{1 4 , 9 0 0}$ & $\mathbf{8 6 2 . 5}$ & $\mathbf{5 7 . 8 8}$ \\
\hline
\end{tabular}

The Intergovernmental Panel on Climate Change's 2006 Guidelines for National Greenhouse Gas Inventories (referred to here as the "IPCC 2006 Guidelines") [37] advised governments to use another biome type system, devised by FAO [38], when reporting the Agriculture, Forestry and Other Land Use (AFOLU) flux in their national greenhouse gas inventories. Its tropical forest categories are more disaggregated than in Whittaker's system [35] (Table 2). Even more disaggregated is the classification of Eyre [39] (Table 2).

\subsection{Completeness and Intergovernmental Reporting Guidelines}

The completeness of estimates of carbon fluxes included in government reports to the UNFCCC may be evaluated by referring to reporting guidelines that specify the fluxes for which estimates are required (but these guidelines can also restrict the scope of estimates). 
Table 2. Classifications of tropical biome types by the UN Food and Agriculture Organization (FAO)/Intergovernmental Panel on Climate Change (IPCC) [37,38] and Eyre [39].

\begin{tabular}{llll}
\hline FAO/IPCC & \multicolumn{2}{l}{ Eyre } & \\
\hline 1. Tropical rain forest & 1. & Tropical rain forest \\
2. Tropical moist deciduous forest & 2. & Tropical semi-evergreen/deciduous forest \\
3. Tropical dry forest & 3. & Monsoon forest \\
4. Tropical shrub land & 4. & Tropical deciduous forest \\
5. Tropical desert & 5. & Tropical montane forest \\
6. Tropical mountain systems & 6. & Broadleaved tree savanna \\
& & 7. & Thorn forest \\
& 8. & Thorn tree tall grass savanna \\
& 9. & Thorn tree desert grass savanna \\
& 10. & Cactus scrub \\
& 11. & Cactus scrub with desert grass \\
& 12. & Desert \\
\hline
\end{tabular}

The Marrakesh Accords agreed by the UNFCCC in 2001 for implementing the Kyoto Protocol defined key mitigating actions in the Land Use Change and Forestry (LUCF) sector [40,41]. This drew on a report by the IPCC [29] which showed, for example, that more than 240 different definitions of 'forest' are in use [42]. A key difference between definitions in the Marrakesh Accords and those in Section 2.1 is that forest is "a minimum area of land of 0.05-1.0 hectares with tree crown cover (or equivalent stocking level) of more than 10-30 percent with trees with the potential to reach a minimum height of 2-5 metres at maturity in situ. A forest may consist either of closed forest formations or open forest" [40].

According to the UNFCCC 2011 Guidelines for submitting National Greenhouse Gas Inventories, governments should divide emissions estimates into six categories: (a) Energy; (b) Industrial Processes; (c) Solvents; (d) Agriculture; (e) Land Use Change and Forestry (LUCF); (f) Waste. The LUCF flux is further divided into: (i) changes in forest and other woody biomass stocks; (ii) forest and grassland conversion; (iii) abandonment of managed lands; (iv) $\mathrm{CO}_{2}$ emissions and removals from soils; and (v) "other" (Table 3) [43]. The latter provides a model of land use and land cover change which incorporates: (a) changes resulting from deforestation and conversion of grasslands to other land uses ("forest and grassland conversion"); (b) the reversal of deforestation by afforestation/reforestation as croplands and grasslands are abandoned ("abandonment of managed lands"); (c) changes in forest carbon stocks arising from human disturbance short of clearance, i.e., degradation or its reversal ("changes in forest and other woody biomass stocks"); and (d) $\mathrm{CO}_{2}$ emissions and removals from the atmosphere by soils. These categories cover most of the principal emissions and removals fluxes, but aggregate those for "forest and grassland conversion".

Table 3. Land Use Change and Forestry (LUCF) categories in the UN Framework Convention on Climate Change (UNFCCC) 2011 Reporting Guidelines [43] and corresponding Agriculture, Forestry and Other Land Use (AFOLU) categories in the Intergovernmental Panel on Climate Change (IPCC) 2006 Guidelines [37].

\begin{tabular}{llll}
\hline UNFCC & LUCF Categories & \multicolumn{2}{l}{ IPCC AFOLU Categories } \\
\hline 1. & Changes in forest and other woody biomass stocks & 1. & Forestland \\
2. & Forest and grassland conversion & 2. & Cropland \\
3. & Abandonment of managed lands & 3. & Grassland \\
4. & $\mathrm{CO}_{2}$ emissions and removals from soils & 4. & Wetlands \\
5. & Other & 5. & Settlements \\
& & 6. & Other land \\
& & 7. & Harvested wood products \\
\hline
\end{tabular}


The completeness of National Greenhouse Gas Inventories (NGGIs) submitted by different countries may in practice differ from the UNFCCC 2011 Guidelines [43] because:

1. The UNFCCC also allows governments to follow the IPCC 2006 Guidelines [37]. This can have two contrasting effects:

a. Greater completeness. Transfers of land between the various uses listed in the IPCC 2006 Guidelines represent a more comprehensive matrix model of land use and land cover change than in the UNFCCC model (Table 3) and include the main types of forest area change fluxes. Changes in carbon stocks without any land-use change, e.g., forest degradation and its reversal, are shown in the diagonal cells in the matrix (Figure 2). Forest and grassland are not combined, as in the UNFCCC model, so the deforestation flux is now clearly specified.

Forestation

\begin{tabular}{|c|c|c|c|c|c|c|}
\hline Initial & Forest land & Cropland & Grassland & Wetland & Settlement & Other land \\
\hline Forest land & $\bullet$ & & & & & \\
\hline Cropland & & $\bullet$ & & & & \\
\hline Grassland & & & $\bullet$ & & & \\
\hline Wetland & & & & $\bullet$ & & \\
\hline Settlement & & & & & $\bullet$ & \\
\hline Other land & & & & & & $\bullet$ \\
\hline
\end{tabular}

Figure 2. An abbreviated version of the Intergovernmental Panel on Climate Change 2006 matrix model of transfers between land uses [37].

b. Less completeness. The IPCC 2006 Guidelines only have five main reporting categories: (a) Energy; (b) Industrial Processes and Product Use; (c) Agriculture, Forestry and Other Land Use (AFOLU); (d) Waste; and (e) Miscellaneous. Combining the UNFCCC Agriculture and LUCF categories in the AFOLU category underspecifies forest carbon fluxes [37].

2. Governments may not provide estimates in all possible reporting categories. While the IPCC [44] specifies "completeness" as one of four good reporting practices, a Tier System described in the IPCC 2006 Guidelines gives governments the flexibility to decide how complete their reports of carbon fluxes are, and how much they disaggregate forest types and fluxes [37], as their monitoring capacity may be limited [45]. These tiers involve using:

a. Global default values of two types of parameters when national empirical data are lacking: (i) "activities", such as deforestation rates; and (ii) "emission factors", which convert activities into carbon fluxes (Tier 1).

b. Combinations of global default values of parameters and nationally specific values where these are available (Tier 2).

c. Nationally specific values of parameters (Tier 3).

The contents of Forest Reference Emission Level reports submitted by different countries may also differ in completeness and disaggregation because:

1. Governments do not provide estimates in all possible emissions and removals categories in the historical baselines which they submit.

2. Governments may structure emissions categories in their reports in different ways. The guidelines for Forest Reference Emission Level reports (and for reports on how emissions are reduced relative to these levels) are less detailed than the UNFCCC 2011 Guidelines and appear to give countries more flexibility in determining their structure and content [34]. However, reports are supposed to meet certain criteria, e.g., by being "transparent" and "consistent" with UNFCCC and IPCC 
reporting guidelines, and describing the methodologies used to construct estimates. Complying with these criteria can lead to the inclusion of far more detail and disaggregation than in NGGIs.

\subsection{Assessing Uncertainties}

The Parties to the UNFCCC are required to assess uncertainties in their NGGIs, using a quantitative approach described in the IPCCC 2006 Guidelines. Yet the aim is more to help reduce uncertainties in future submissions than to highlight the limitations of current reports [27]. Since a full statistical analysis of errors may not be possible in practice, the UNFCCC advises governments to refer to uncertainties estimated earlier for "typical sources taken to be representative of the population." However, owing to data limitations, most of the examples of uncertainties listed for this purpose in the IPCC 2006 Guidelines are based on studies of temperate and boreal forests, not tropical forests.

Uncertainty assessments are not required in Forest Reference Emission Level reports [34], though governments often include them voluntarily.

\section{Literature Review}

Uncertainty is defined as "incomplete knowledge" by Böschen et al. [46] but has a contested meaning. Thus, Wynne [47] has identified four "kinds of uncertainty": risk, which can be assessed by probabilities; uncertainty, in which "we don't know the odds"; ignorance, in which "we don't know what we don't know"; and indeterminacy, which is an inability to classify "things ... as the same or different, [based on] specific properties or criteria".

The conventional quantitative approach to evaluating uncertainty, adopted by Pelletier et al. [11] for REDD+ analysis, uses statistical methods to estimate errors. Yet Van der Sluijs has argued that this approach is less meaningful when "unquantifiable uncertainties ... dominate the quantifiable ones" [15]. This often occurs with global environmental change phenomena. Funtowicz and Ravetz have proposed that in such cases quantitative assessment, e.g., of random errors, and systematic errors incurred through unreliable measurement, should be combined with qualitative assessment which interrogates "the underpinning of the numbers and scientific status of the knowledge used" [48].

These arguments imply that quantitative assessments of uncertainties associated with estimates of national and global forest carbon budgets may only be reliable after uncertainties fall below a critical threshold, and until then it is more appropriate to integrate quantitative assessments with qualitative assessments. Indications on how to do this are provided by three taxonomies of sources of uncertainty. Funtowicz and Ravetz have distinguished between sources related to conceptualization, which they called "epistemological", or how well scientific theories fit the real world, and two other types of sources related to measurement: "technical", or random errors, and "methodological", or unreliable measurement [48]. Regan et al. have separated "linguistic" sources of uncertainty, such as indeterminacy and underspecification, which limit conceptualization, from "epistemic" sources, which combine measurement difficulties, such as systematic errors, and natural variability [49]. Van Asselt and Rotmans have divided sources into two groups: "variability" in phenomena and "limited knowledge" sources that relate to measurement [50]. They do not discuss conceptualization sources. These studies suggest that uncertainties about a phenomenon are best divided into those related to its inherent features and those linked to human capacities to conceptualize and measure them. Yet as none of the taxonomies allocate sources between these three categories there is a need for a new framework that can do this.

\section{Methodology and Methods}

\subsection{Uncertainty Assessment Framework}

The Uncertainty Assessment Framework (UAF) was devised to fill this gap [20]. If uncertainty involves "incomplete knowledge" [46] then it is logical to explain it by analysing the disparity between complete knowledge of the state of a phenomenon, based on its inherent features, and present 
knowledge, which is restricted by difficulties in constructing knowledge through conceptualization and measurement and synthesis of the resulting information [51].

The UAF divides sources of uncertainty into three corresponding categories (Table 4):

1. The features of a phenomenon, which determine the extent of complete knowledge about it and the overall scope for uncertainty. The larger and more complex a phenomenon is, the more knowledge is required to understand it properly, the more opportunities there are for information gaps to emerge, and the greater its inherent uncertainty. So a global phenomenon is generally more uncertain than a national phenomenon; and forest carbon change, which has two biophysical attributes (forest area and carbon density), is more uncertain than forest area change, which has just one attribute (forest area). Uncertainty also arises from randomness in the distribution of a phenomenon and through the diversity of human-environment interactions which it involves.

2. Insufficient capacity to conceptualize the phenomenon. This leads to: (a) terminological difficulties, in which the use of unclear, poorly defined or group-specific terms to name and represent a phenomenon and its attributes leads to confusion or ambiguity; (b) underspecificity, involving a lack of detail in statements describing the multiple attributes of a phenomenon, which limits the completeness of these statements; (c) understructuralization, in which classifications of these attributes are insufficiently detailed to fully represent its complexity and disaggregation; and (d) the use of proxies, which may represent attributes by indicators only loosely related to the variables most directly linked to these attributes, or entire phenomena by models constructed with easily quantified variables.

3. Insufficient capacity to measure the phenomenon. This leads to: (a) random errors in measured data; (b) systematic errors in measured data, resulting from, for example, the use of equipment with insufficient resolution to observe a phenomenon properly, or of sampling designs that allow data to be misinterpreted; (c) scalar deficiencies in measurement, which can involve short-cuts or approximations in measuring large phenomena, as in the trade-offs mentioned in Section 1; and (d) the use of subjective judgment in making estimates, in response to the other measurement difficulties [20].

Table 4. Categories of sources of uncertainty in the Uncertainty Assessment Framework.

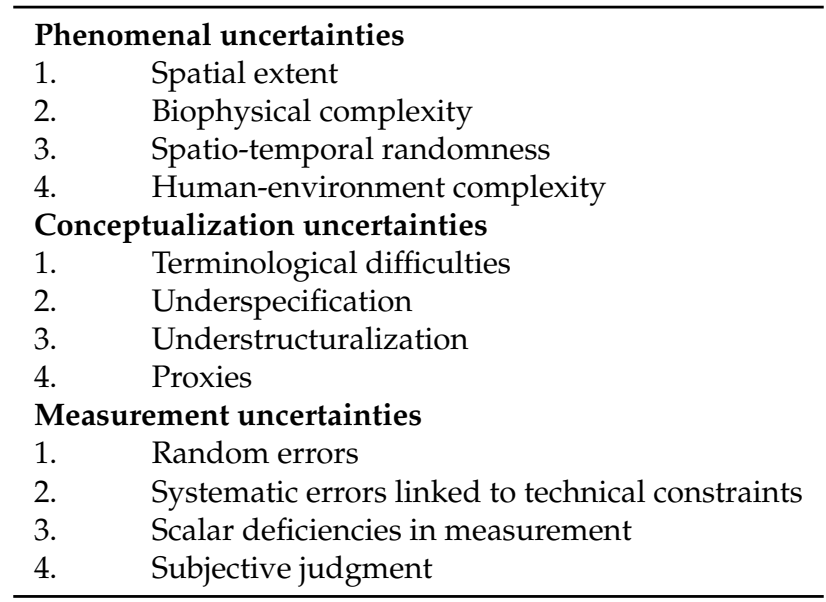

The UAF can explain the underlying causes of environmental uncertainties in terms of societal influences on the two capacities (Figure 3). This is discussed in detail elsewhere [20], together with how this taxonomy relates to the taxonomies of Regan et al. [49] and Van Asselt and Rotmans [50], and how the UAF approaches the classical quantitative method as uncertainty declines and only random and systematic errors remain. 


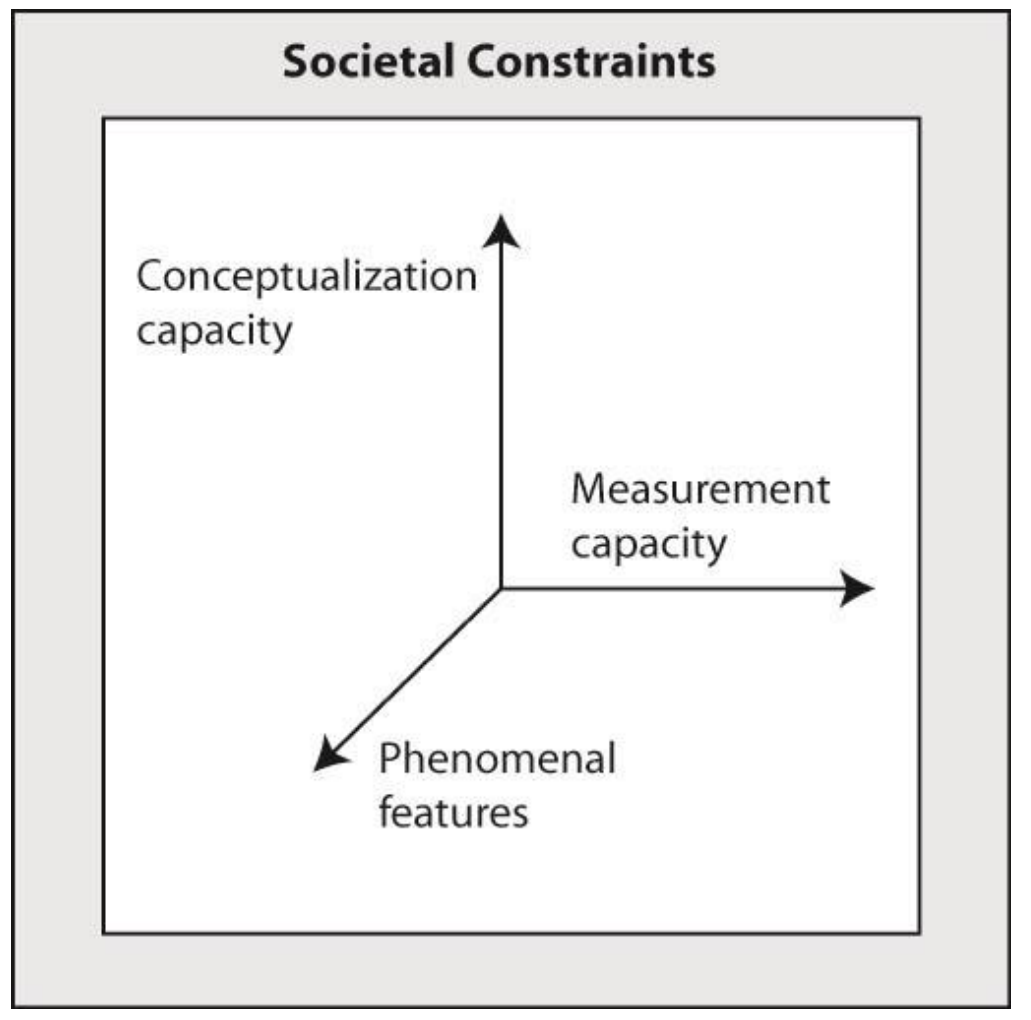

Figure 3. The Uncertainty Assessment Framework.

\subsection{Uncertainties in the Three Dimensions of Earth Observation}

In this paper, the UAF is extended to include Earth observation, which can undertake the direct planetary measurement needed to reduce global environmental uncertainties. If Earth observation science integrates the features of sensors and Earth surface features then it is logical for Earth observation to have three dimensions: spatial, vertical and temporal. In ideal direct planetary measurement there would be a perfect match between spatial, vertical and temporal variation in Earth surface features and the resolutions of the three corresponding dimensions of Earth observation, which include not only the operational resolutions of sensors and their collection of data, supported by ground data, but also the effective resolutions of information generated by processing these data [17].

If measurement is not ideal then conceptualization and measurement uncertainties associated with estimates of multiple attribute global environmental phenomena will occur in each dimension through a mismatch between them and actual Earth surface features and can be evaluated using norms specific to that dimension. In the case of forest carbon change:

1. Spatial uncertainty is concerned with the spatial distribution of ecosystems and particularly their area attribute. It relates to a norm of using optimum resolution optical sensors to map changes in the areas of different features on the ground according to the spectral reflectances of their vegetation canopies [52].

2. Vertical uncertainty refers to the height, depth and complexity of ecosystems and their carbon attribute in layers above and below the ground. It relates to a norm of using (especially) non-optical sensors supported by ground data, both at optimum resolution, to measure changes in the biomass densities of the various components of ecosystems.

3. Temporal uncertainty is linked to rates of change in the distribution of ecosystems and their carbon attribute over time. It relates to a norm of using sensors whose operational frequencies of data collection match the temporal variation of ecosystem features and utilizing data at frequencies that fully benefit from the operational frequencies of sensors. 
The UAF predicts that uncertainties associated with direct measurements of ecosystems should fall as the resolutions of the three dimensions of Earth observation rise. Thus:

1. Spatial uncertainty should decline as the spatial resolution of sensors employed for monitoring increases since this enables: (a) more accurate measurement of deforestation and forestation for different forest types; and (b) more accurate measurement of spatial forest degradation, which reduces tree density.

2. Vertical uncertainty should decline as the design of monitoring and deployment of individual and multiple data collection methods allow better vertical resolution, e.g., by: (a) greater use of non-optical satellite data, to track vertical degradation linked to changes in vegetation structure and canopy height; (b) greater disaggregation of natural and modified ecosystems with different carbon densities; and (c) better collection of ground data, to provide more accurate information on the sizes of various carbon pools, and on other vegetation features needed to ground-truth remote sensing data.

3. Temporal uncertainty should decline as a rise in the temporal resolution of sensor and ground data, and their use, distinguishes better between: (a) deforestation and forestation; and (b) forest degradation and subsequent regeneration.

\subsection{Coding the Uncertainty Fingerprint of an Estimate}

The Uncertainty Fingerprint of an estimate of forest carbon fluxes is coded in six stages:

1. Estimates of forest carbon fluxes are grouped into those for:

a. Carbon dioxide $\left(\mathrm{CO}_{2}\right)$ emissions resulting from: (i) deforestation, and the subsequent burning of vegetation and soil; and (ii) logging and other types of forest degradation.

b. $\quad \mathrm{CO}_{2}$ removals arising from: (i) forest (re)growth, which includes both regrowth in regenerating logged forest and growth in mature forest [26]; and (ii) forestation, i.e., afforestation on historically cleared land and reforestation following land abandonment [25].

2. The estimate which is the focus of a government report or scientific paper is identified so the uncertainty assessment can refer to it.

3. Information provided with each estimate is used to assess the spatial, vertical and temporal dimensions of its uncertainty (see Supplementary Material).

4. The presence of the different types of conceptualization and measurement uncertainties (Table 4) in each dimension is identified and coded as follows:

a. Spatial dimension: terminological difficulties $\left(\mathrm{t}_{\mathrm{sp}}\right)$; underspecification uncertainties linked to area change fluxes, e.g., not referring to deforestation, reforestation, or afforestation

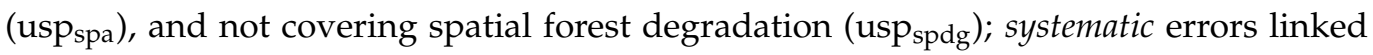
to measuring forest area change (sysp) and visually analysing photographic versions of satellite images ( $\left.\mathrm{sy}_{\mathrm{vis}}\right)$; scalar deficiencies (sc); and subjective judgment (su).

b. Vertical dimension: terminological difficulties $\left(t_{v}\right)$; underspecification uncertainties linked to the coverage of fluxes that reduce or increase carbon pools, e.g., vertical degradation and (re)growth ( $\mathrm{usp}_{\mathrm{v}}$ ); understructuralization uncertainties linked to the number of carbon pools reported (ust $\mathrm{pool}_{\text {) }}$ ), the number of ecosystem types included (ust $\mathrm{ecol}_{\text {) }}$ ), and whether land cover changes in carbon densities (ust $\mathrm{t}_{\mathrm{lc}}$ ) are reported; systematic errors linked to the measurement of forest biomass change $\left(\mathrm{sy}_{\mathrm{v}}\right)$; and the use of proxies, e.g., basing estimates of logging degradation on wood production volumes $\left(\mathrm{pr}_{\log }\right)$.

c. Temporal dimension: systematic errors linked to the frequency of spatial $\left(\mathrm{T}_{\mathrm{sp}}\right)$ and vertical $\left(\mathrm{T}_{\mathrm{V}}\right)$ mapping and reporting. 
5. The fingerprint is assembled for each dimension in turn by combining the codes shown above in shorthand or graphical forms. In the shorthand form groups of conceptualization uncertainties are prefixed by the letter $\mathrm{C}$ and measurement uncertainties by the letter $\mathrm{M}$.

6. The total number of uncertainties in a fingerprint gives its Uncertainty Score.

\subsection{Ranking Completeness and Disaggregation}

The completeness of any estimate of forest carbon fluxes is ranked here from 0 to 6 by the number of fluxes which it reports, i.e., those related to deforestation, spatial and vertical forest degradation, afforestation, reforestation and (re)growth.

The disaggregation of any estimate of forest carbon fluxes is ranked by:

1. The number of carbon pools in the six fluxes. This includes Zero pools; Low (1): above- and/or below-ground biomass; Medium: above- and below-ground biomass plus one of the following: deadwood, litter and soil (2); and High: all the pools (3).

2. The number of ecosystem types into which forest is divided for carbon accounting. By referring to the full range of ecosystem types shown by global classifications e.g., [39], ecosystem stratification is ranked and scored as Zero, Low (1), Medium (2) and High (3).

3. Whether estimates of emissions following land cover change include the biomass of the new land cover (net) or exclude it (gross). Gross estimates are scored 0 and net estimates 1.

\subsection{Data}

The UAF is applied to evaluate government reports submitted to the UNFCCC by twelve developing countries-Brazil, Cambodia, Democratic Republic of the Congo, Costa Rica, Ghana, Indonesia, Laos, Malaysia, Mexico, Nigeria, Peru and Tanzania-which cover all three tropical regions and contain half of total tropical forest area [53]. From the uncertainties associated with estimates of forest carbon fluxes in these reports may be inferred the quality of the Earth observation systems that produced them, in this case, government Measurement, Reporting and Verification (MRV) centres [13]. These reports include:

1. National Greenhouse Gas Inventories (NGGIs) contained in National Communications submitted between 2011 and 2016 by the governments of Brazil [54], Cambodia [55], Democratic Republic of the Congo [56], Costa Rica [57], Ghana [58], Indonesia [59], Laos [60], Malaysia [61], Mexico [62], Nigeria [63], Peru [64] and Tanzania [65] (Supplementary Tables S1-S2). These should be typical of reports to the Global Stocktake.

2. Forest Reference Emission Level (FREL) reports submitted from 2016 to 2019 by the governments of Brazil [66], Cambodia [67], Democratic Republic of the Congo [68], Costa Rica [69], Ghana [70], Indonesia [71], Laos [72], Malaysia [73], Mexico [74], Nigeria [75], Peru [76] and Tanzania [77] (Tables S3 and S4). These should typify progress reports to REDD+.

Estimates of carbon fluxes in government reports to the UNFCCC refer to the mass of carbon dioxide $\left(\mathrm{CO}_{2}\right)$ (not carbon) in gigagrams $(\mathrm{Gg})$ of $\mathrm{CO}_{2}\left(1 \mathrm{Gg}=10^{9} \mathrm{~g}\right)$ for NGGIs and tonnes of $\mathrm{CO}_{2}\left(1 \mathrm{t}=10^{6} \mathrm{~g}\right)$ for FREL reports. Here these are both converted into Megatonnes (Mt) of $\mathrm{CO}_{2}$ $\left(1 \mathrm{Mt}=10^{6}\right.$ tonnes). Emissions of other greenhouse gases, such as methane and nitrous oxide, are aggregated with actual emissions of $\mathrm{CO}_{2}$ to give "emissions for all gases" in units of tonnes of carbon dioxide equivalent warming potential $\left(\mathrm{CO}_{2} \mathrm{e}\right)$.

\section{Results}

This section uses the Uncertainty Assessment Framework (UAF) to evaluate uncertainties associated with estimates of forest carbon fluxes submitted to the UNFCCC by the governments of twelve tropical countries. After an overview of the estimates themselves, it examines each of the sources of spatial, vertical and temporal uncertainties in turn, combines these sources to construct the 
Uncertainty Fingerprint of each estimate, and then discusses the insights provided by the fingerprints into the reliability of these estimates.

\subsection{Overview of Estimates}

To assess the reliability of estimates of forest carbon fluxes submitted to the first UNFCCC Global Stocktake by its member countries in their National Greenhouse Gas Inventories (NGGIs) the UNFCCC should compare estimates for common reporting categories. Yet if our sample of NGGIs is representative, this will be constrained qualitatively by the structure of the reporting guidelines adopted by each government and its selective use of that structure. For instance, our twelve sample countries do not all supply estimates in each of the three total $\mathrm{CO}_{2}$ reporting categories for Land Use Change and Forestry (LUCF). Some report "Total LUCF CO Emissions", while others report "Total LUCF CO $_{2}$ Removals", or the difference between them, i.e., "Net LUCF $\mathrm{CO}_{2}$ Emissions". The only total category estimated in every NGGI is "National Net Emissions of All Greenhouse Gases" (Table S5).

Such incompleteness, if it persists, will make it difficult to use the same set of estimates to calculate the overall contribution of forests to the greenhouse effect in the Global Stocktake. For example, only seven NGGIs (for Brazil, Cambodia, Democratic Republic of the Congo, Indonesia, Laos, Malaysia and Nigeria) include estimates of Net LUCF CO $\mathrm{C}_{2}$ Emissions in the 2000s and estimates of National Net $\mathrm{CO}_{2}$ Emissions from all sources. Their combined Net LUCF CO${ }_{2}$ Emissions are $1003 \mathrm{MtCO}_{2} \mathrm{a}^{-1}$ or $45 \%$ of their National $\mathrm{Net}^{\mathrm{CO}_{2}}$ Emissions of $1,959 \mathrm{Mt} \mathrm{CO}_{2} \mathrm{a}^{-1}$ (Table $5 \mathrm{a}$ ).

Table 5. Aggregate emissions in the 2000s of carbon dioxide $\left(\mathrm{CO}_{2}\right)$ from the Land Use Change and Forestry (LUCF) sector, all national sectors, and deforestation only, reported in the National Greenhouse Gas Inventories (NGGIs) and Forest Reference Emission Level (FREL) reports of two groups of countries [54-77].

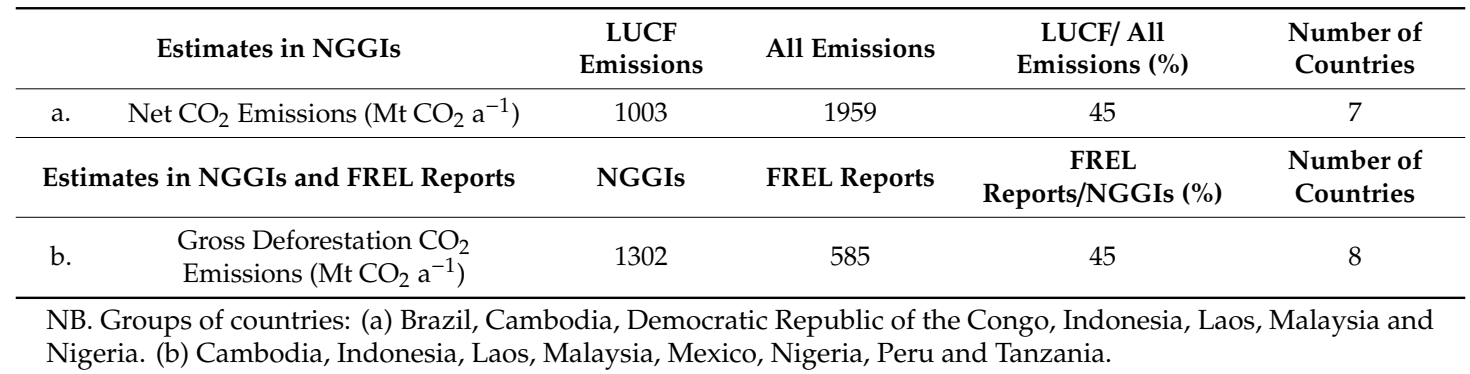

It will be more challenging to compare the reliability of different sets of estimates of LUCF/forest $\mathrm{CO}_{2}$ emissions, e.g., (a) estimates for the same year or period made for the Global Stocktake by the UNFCCC and the IPCC (for example, its synthesis of scientific estimates of pan-tropical forest $\mathrm{CO}_{2}$ emissions); or (b) estimates for different years reported to REDD+ by participating countries to show they have reduced their emissions. Simulating these actions here by comparing NGGI estimates with estimates made by the same countries in their Forest Reference Emission Level (FREL) reports is also constrained by the limited number of common reporting categories for which estimates are submitted. For example, only three FREL reports have estimates for all three total categories, compared with six NGGIs. Six FREL reports include no estimates for any total category (Figure S1).

Coverage of the six forest carbon fluxes linked to deforestation, spatial and vertical degradation, afforestation, reforestation and (re)growth is also incomplete. Only one FREL report estimates five fluxes, while two NGGIs and one FREL report estimate four fluxes (Figure S2). All the FREL reports estimate emissions from deforestation, but this is the only flux estimated by seven countries (Table S3). Only eight countries - Cambodia, Indonesia, Laos, Malaysia, Mexico, Nigeria, Peru and Tanzania estimate deforestation emissions in their NGGIs (Table S1). Yet the sum of the estimates in their FREL reports $\left(585 \mathrm{MtCO}_{2} \mathrm{a}^{-1}\right)$ is only $45 \%$ of their NGGI estimates (1302 $\mathrm{Mt} \mathrm{CO}_{2} \mathrm{a}^{-1}$ ) (Table 5b). 
The two sets of estimates may differ because deforestation rates are estimated over different periods, and/or the FREL estimate is more accurate for the same period. The mean year for the NGGI estimates is 2007 and for the FREL estimates is 2008, but the FREL estimates are means over at least ten years (22 years for Indonesia) from 1990 to 2016, while the NGGI estimates are for single years from 2000 to 2014. As none of the NGGIs lists the deforestation rate on which the corresponding emissions estimate is based (Table S2) an exact comparison with each country's deforestation rate in the FREL reports is not possible. Yet the sum of government estimates of deforestation rates in FAO forest statistics [53] for the nearest periods to the FREL estimates $\left(2.0 \mathrm{Mha} \mathrm{a}^{-1}\right)$ is only $64 \%$ of the equivalent sum for the NGGI estimates (3.2 Mha a ${ }^{-1}$ ). This is consistent with information in the FREL reports (Table S6).

Since the difference between the sets of estimates in Table $5 \mathrm{~b}$ is also influenced by uncertainties generated in converting deforestation rates into carbon emissions, in the rest of this section we interrogate these uncertainties. It is not practical to compare estimates for more fluxes, since of the five countries which include estimates for more than one flux in their FREL reports only three do so in their NGGIs. Because FREL reports do not use LUCF variables, we now refer to "forest carbon fluxes", not "LUCF carbon fluxes".

\subsection{Sources of Spatial Uncertainty}

Sources of spatial uncertainty mainly relate to estimates of forest area change, which ideally would be derived from measurements using optical satellite images. This sub-section looks in turn at the three sources of spatial uncertainty found in flux estimates in the NGGIs and FREL reports: terminological difficulties and underspecification (forms of conceptualization uncertainty), and systematic errors (a form of measurement uncertainty) (Table 4).

\subsubsection{Terminological Difficulties}

The most common spatial terminological difficulty involves using different definitions of terms. The IPCC 2006 Guidelines allow governments to define 'forest' as existing above a minimum threshold of between $10 \%$ and $30 \%$ tree cover [37]. Any definitions within this range will be consistent with the IPCC rule, but will exacerbate inherent uncertainty when forest fluxes are aggregated in the Global Stocktake. If governments opt for a threshold above the FAO definition of $10 \%$ (see Section 2.1) this will reduce rates of deforestation and forestation and limit comparability between government estimates of net emissions in the Global Stocktake and scientific pan-tropical estimates that follow the FAO definition.

None of the twelve NGGIs in our sample state the minimum percentage tree cover adopted to define 'forest', and so all have terminological difficulties (Tables S2 and S7). In contrast, all countries state their chosen definition in their FREL reports. Brazil, Cambodia, Mexico, and Tanzania use a $10 \%$ threshold; Ghana and Nigeria 15\%; Laos 20\%; and Democratic Republic of the Congo, Indonesia, Malaysia and Peru 30\%. These are within the range allowed in the IPCC 2006 Guidelines [37], but Costa Rica's report, which adopts a 70\% threshold, is outside the range and so has terminological difficulties (Tables S4 and S7).

\subsubsection{Underspecification Uncertainties}

Two types of underspecification limit completeness in reporting the four spatial carbon fluxes:

1. Underspecification of area change. All twelve NGGIs are spatially underspecified. Four report none of the three forest area change fluxes: Brazil, Democratic Republic of the Congo and Ghana follow the UNFCCC 2011 Reporting Guidelines [43] and only estimate emissions for the composite category of "forest and grassland conversion", not deforestation, while Costa Rica follows the IPCC 2006 Guidelines [37] and only reports total emissions from Agriculture, Forestry and Other Land Use. Mexico, Nigeria and Tanzania report deforestation emissions but not removals by reforestation or afforestation. Cambodia, Indonesia, Laos, Malaysia and Peru estimate deforestation and reforestation fluxes but omit the afforestation flux (Table 6 and Table S1). 
The FREL reports for six countries only estimate Gross Deforestation $\mathrm{CO}_{2}$ Emissions (see Section 5.5.2) but all are fully specified as this is the intended reporting total. Indonesia's report is fully specified too as it reports Total Forest $\mathrm{CO}_{2}$ Emissions, i.e., emissions from deforestation and degradation (Tables 6 and S3). The other five countries all report emissions from deforestation and do attempt to estimate Net Forest $\mathrm{CO}_{2}$ Emissions, but of these only the Laos estimate is spatially complete. The rest omit the afforestation or reforestation fluxes.

2. Underspecification of spatial forest degradation. Spatial forest degradation involves a decline in tree density and canopy closure [23]. Not measuring it underestimates the emissions resulting from degradation, but overestimates emissions from deforestation of degraded forest. For convenience, it is evaluated on a continuous scale as a reversible flux. All twelve NGGIs are underspecified in this way as none estimates carbon fluxes for spatial forest degradation. Only one FREL report does so: that for Ghana divides each of the country's seven ecosystem types into closed forest and open forest categories (Table 6).

Table 6. Spatial and vertical underspecification uncertainties: the presence or absence of estimates of forest carbon fluxes in the National Greenhouse Gas Inventories (NGGIs) and Forest Reference Emission Level (FREL) reports of twelve tropical countries [54-77], showing in italics the set of eight countries whose estimates are compared in Table $5 b$.

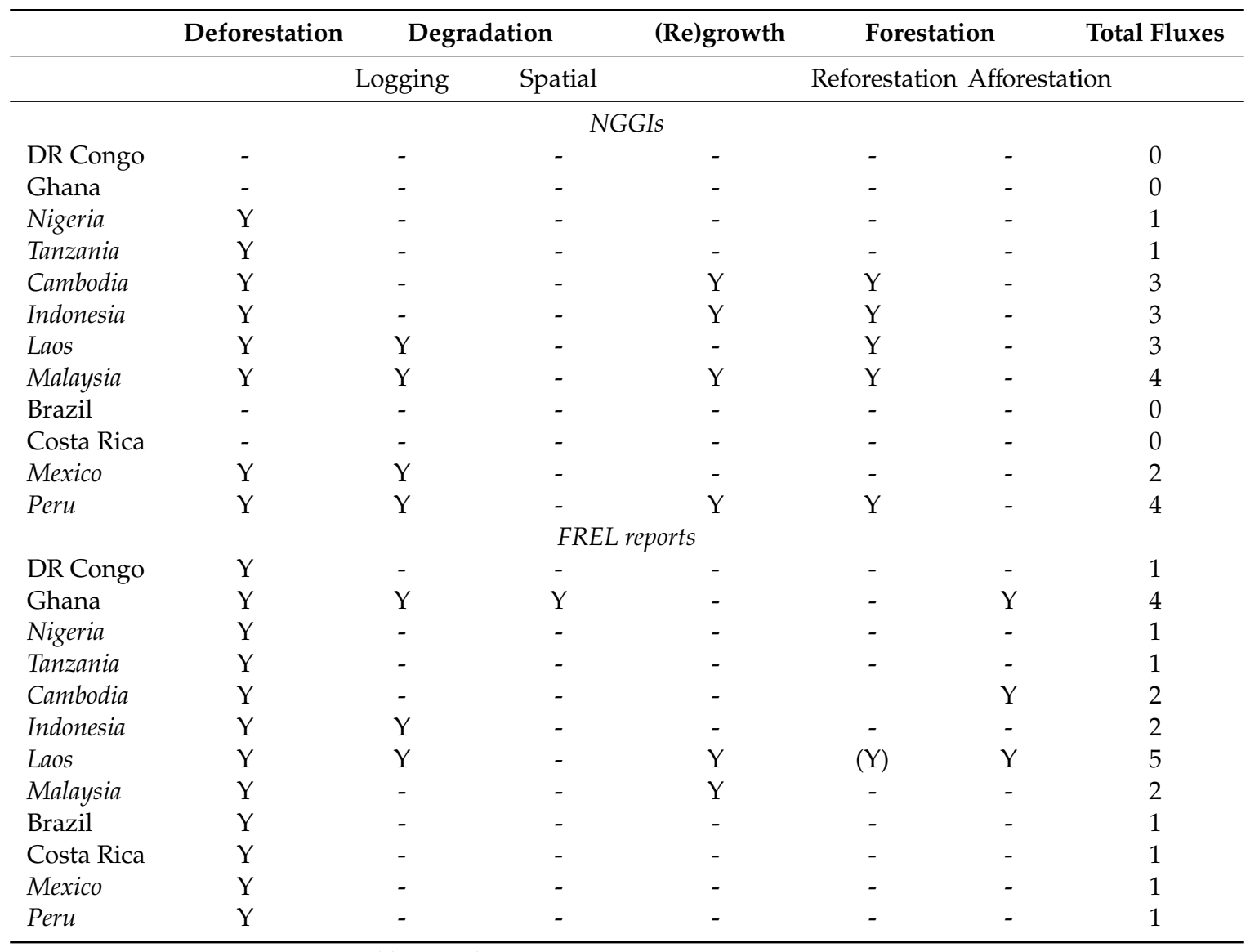

NB. Y = inclusion of flux; - = flux is not included; $(\mathrm{Y})$ = included, but in another category.

\subsubsection{Systematic Errors Resulting from Using Data with Insufficient Spatial Resolution}

Systematic errors are introduced into estimates of forest area change, and estimates of forest carbon fluxes derived from them, if they are based on spatial data which have:

1. Insufficient sensor resolution to separate forest from non-forest. Only the NGGIs for Brazil, Costa Rica and Peru state that their estimates of forest change are based on satellite data with at least 
the medium $(20-100 \mathrm{~m})$ resolution needed to identify the full range of sizes of forest clearances observed in the tropics (i.e., $\geq 1$ ha). For other countries, the highest quality of source data cited are "maps" or "statistics", with no measurements mentioned (Table S7). All the FREL reports are based on at least medium resolution satellite data (Table S7).

2. Insufficient resolution to distinguish between deforestation and forestation when classifying remotely sensed data. Most of the NGGI and FREL estimates which are based on satellite data use visual analysis of photographic image products (Table S7). This can underestimate both deforestation and forestation, as the minimum patch size it can distinguish is below sensor resolution, e.g., 6 ha for $30 \mathrm{~m}$ Landsat images.

\subsection{Sources of Vertical Uncertainty}

Forest carbon change differs from forest area change by occurring in three, not two, dimensions in space, and involving changes in the complex vertical distribution of the carbon attribute from the tips of trees in forests to the extremities of roots below the ground surface. Sources of vertical uncertainty relate to estimates of changes in carbon densities which ideally would be derived from non-optical satellite images and ground measurements, but are also linked to mapping ecosystem types and land cover using optical images. This sub-section looks in turn at the four sources of vertical uncertainty found in the estimates reviewed here: terminological, understructuralization, systematic errors and underspecification (Table 4).

\subsubsection{Terminological Difficulties}

As with spatial uncertainties, uncertainty can arise if terms are not defined properly. For example, there is no formal UNFCCC definition of "forest degradation" even though it is a major component of REDD+! The term is not even mentioned in the IPCC 2006 Guidelines, though the IPCC [78] had earlier proposed that "forest degradation" could be defined as "A direct human-induced long- loss (persisting for $\mathrm{X}$ years or more) of at least $\mathrm{Y} \%$ of forest carbon stocks (and forest values) since time $\mathrm{T}$ and not qualifying as deforestation or an elected activity under Article 3.4 of the Kyoto Protocol". Countries following the UNFCCC and IPCC reporting guidelines may report forest degradation, e.g., within the categories of "changes in forest and other woody biomass stocks" [43] or "forest remaining as forest" [37], even if they do not describe it as such. So this terminological difficulty affects all the NGGIs and FREL reports evaluated here that include estimates of degradation fluxes (Table 6).

\subsubsection{Understructuralization Uncertainties}

Three types of understructuralization limit disaggregation in flux estimates:

1. Understructuralization by carbon pools. Ideally, estimates of forest carbon fluxes would be disaggregated to include separate estimates of changes in five main pools: above-ground biomass, below-ground biomass, deadwood, litter and soil. Of the twelve NGGIs, only those from Brazil, Ghana and Tanzania do this and so are not understructuralized. The remaining estimates are poorly disaggregated between pools (Tables S1, S2 and S8). All the FREL reports, apart from that of Indonesia, include estimates for above- and below-ground biomass but only Ghana's FREL report is not understructuralized (Tables S3, S4 and S8).

2. Understructuralization by ecosystem types. Estimates of forest carbon fluxes should also ideally be disaggregated into different ecosystem types, as these affect the parameters used to convert timber volume measurements into estimates of biomass and carbon densities [4].

Only three NGGIs disaggregate forest area by ecosystem types (Table S8). Brazil is divided into six biomes - one of which is Amazonia - but is not ecologically disaggregated further. Forests in the Democratic Republic of the Congo are divided into humid, seasonal and dry types, and those in Indonesia into dryland forests, mangrove forests and swamps.

In contrast, all countries distinguish between multiple types of forest ecosystems in their FREL reports, ranging from 3 in Indonesia to 8 in Mexico (Table S8). None of the reports is regarded here as 
ecologically understructuralized as they include at least the same number of biome types as in the global map of Eyre [39] (Table 2), or are close to doing so.

3. Understructuralization by land cover change. Accurate estimates of land cover change should report the net change in carbon density when $\mathrm{CO}_{2}$ emitted after deforestation is offset by $\mathrm{CO}_{2}$ removed from the atmosphere by the vegetation that replaces forest. Actual $\mathrm{CO}_{2}$ emissions will be overestimated if only gross emissions from forest loss are reported.

All twelve NGGIs are understructuralized by land cover change as none states whether it adopts a net or gross approach. The FREL reports of Indonesia and all four African countries specifically report net changes but the rest are understructuralized (Table S8).

The three forms of understructuralization differ in their potential to bias estimates of carbon fluxes and contribute to the contrast between estimates of gross deforestation emissions in the NGGIs (1302 Mt CO $2 \mathrm{a}^{-1}$ ) and FREL reports $\left(585 \mathrm{Mt} \mathrm{CO}_{2} \mathrm{a}^{-1}\right)$ of the eight countries in Table $5 \mathrm{~b}$. Understructuralization by carbon pools restricts the expansion of flux estimates based solely on above-ground biomass change: the "understructuralization pyramid" shows how an estimate of a carbon flux will rise as more pools are included (Figure 4). The mean of 2.6 pools per country in the FREL reports, compared with only 2.0 pools in the NGGIs, would therefore favour a higher, not lower, FREL estimate. Understructuralization by ecosystem types, however, restricts the variance of flux estimates between different carbon density classes. So the mean of just 0.4 ecosystem types in the NGGIs, compared with 5.0 in the FREL reports (Figure S3), reflects a reliance by many NGGIs on aggregated carbon density values that could overestimate carbon emissions, and help to explain the higher NGGI estimate. Understructuralization by land cover change could have the same effect, as it overestimates net emissions, and appears in all the NGGIs but only three FREL reports.

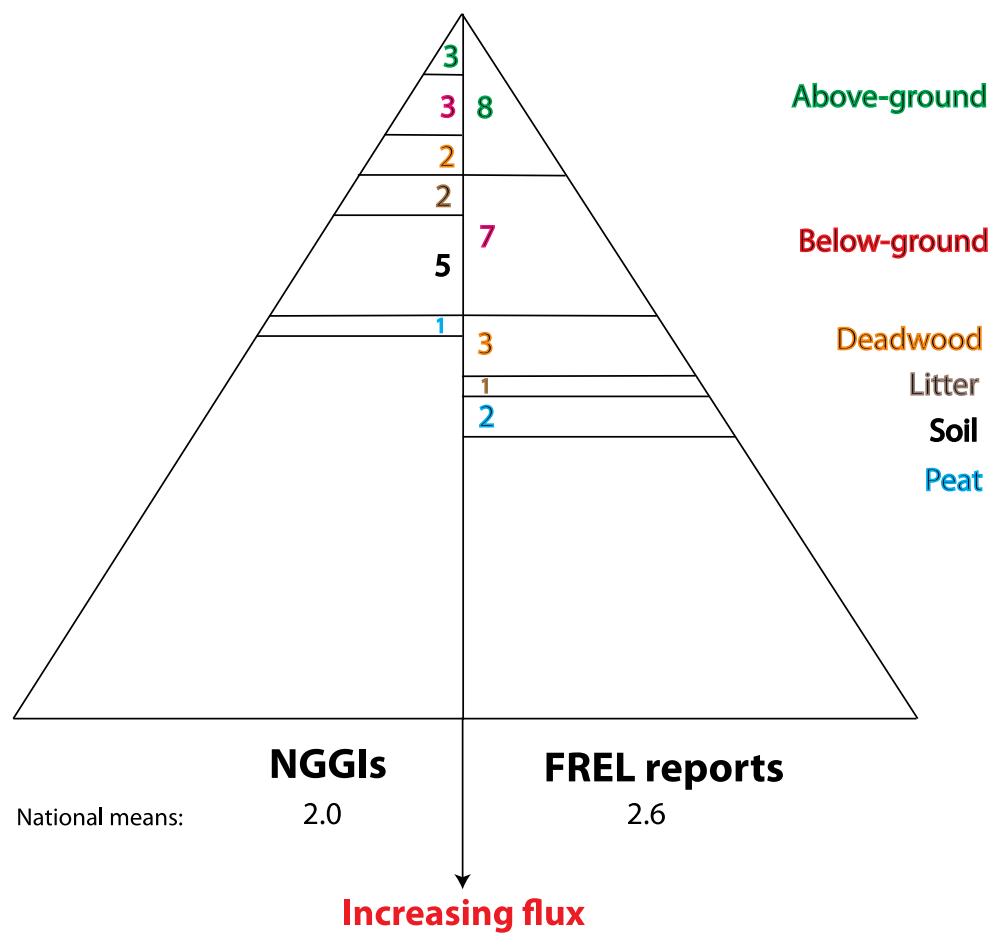

Figure 4. Understructuralization: the total numbers of carbon pools in estimates of forest carbon fluxes in the National Greenhouse Gas Inventories (NGGIs) and Forest Reference Emission Level (FREL) reports of eight tropical countries (see Table 5b) [55,59-65,67,71-77].

\subsubsection{Systematic Errors Resulting from Using Data with Insufficient Vertical Resolution}

Measuring changes in carbon pools with insufficient resolution leads to systematic errors in estimating carbon fluxes but with no common predictable bias. None of the NGGIs uses non-optical 
satellite data. Only the NGGIs of Brazil, Costa Rica, Ghana and Mexico mention the use of forest inventory data. The other countries use "statistics" or list no data sources. In contrast, forest inventory data are the highest quality data source in eleven FREL reports, and ten list the number of inventory plots measured, though only Brazil makes operational use of data from non-optical (radar) sensors (Table S9).

\subsubsection{Underspecification Uncertainties}

Vertical forest degradation and its reversal by regrowth involve structural changes, e.g., a reduction in mean tree height when tall commercial trees are removed in selective logging. Only the NGGIs for Laos, Malaysia, Mexico and Peru estimate $\mathrm{CO}_{2}$ emissions after logging; only Malaysia and Peru estimate how these emissions are offset by regrowth in logged forest; Cambodia and Indonesia merely report $\mathrm{CO}_{2}$ removals in regrowing logged forest (Tables 6 and S1). Only Ghana, Indonesia and Laos estimate the logging degradation flux in their FREL reports. Malaysia reports substantial net $\mathrm{CO}_{2}$ removals in regrowing logged forest (Tables 6 and S3). Estimates of logging degradation commonly follow the IPCC 2006 Guidelines by using national wood production statistics, which is a proxy uncertainty (Table 4). The impact of differing degrees of underspecification on net emissions in different sets of estimates is less straightforward than for understructuralization.

\subsection{Sources of Temporal Uncertainty}

Temporal uncertainties result from infrequent monitoring of forest area and carbon stocks using optical and non-optical sensors, supported by ground data, and involve two types of systematic errors:

1. Not identifying deforestation and forestation. Tropical forest regenerates quickly, so if it is not monitored at least every 3 years then much deforestation and forestation may not be spotted. The resulting systematic errors create a misleading picture of the relative magnitudes of deforestation and forestation [79], underestimating both fluxes, and helping to explain the spatial underspecification described in Section 5.2.2 (Table 6).

Apart from Brazil, all NGGIs have spatial temporal uncertainties (Table S10). To allow for variation in their forest monitoring capacities, developing countries are given flexibility in choosing the temporal resolution of their emissions reports in NGGIs, e.g., "an inventory may estimate emissions and removals for one year or a number of years" [43]. Democratic Republic of the Congo, Ghana, Indonesia, Malaysia and Mexico all provide annual emissions reports in their NGGIs, but there is no evidence that these are based on annual forest area monitoring: only Indonesia's NGGI lists its monitoring frequency (4 years). Brazil has annual forest area monitoring, but only reports emissions every 5 years (Table S2), using detailed land use change matrices that follow the IPCCC 2006 Guidelines (as in Figure 2) [37].

FREL reports give more information on the dates of national forest area surveys so that mean national mapping frequencies can be calculated (Table S10). Only four countries-Indonesia, Malaysia, Brazil and Peru-monitored forest area at least every three years in the FREL period and so have no spatial-temporal uncertainties. As in their NGGIs, Democratic Republic of the Congo, Ghana, Indonesia, Malaysia and Mexico, plus Nigeria, report forest $\mathrm{CO}_{2}$ emissions every year in the reference period even though forest area change is not monitored annually. Peru and Brazil survey their forests every year but have lower reporting frequencies. The remaining countries report mean annual emissions over the entire period (Tables S3 and S10). When evaluating uncertainties associated with estimates of forest carbon fluxes it helps to inspect the area information on which they are based, especially if no reference is made to the use of optical satellite data. Only the NGGIs of Brazil and Democratic Republic of the Congo include these estimates of forest area change, but all countries except Mexico list such estimates in their FREL reports (Table S10).

Owing to lack of information in the NGGIs it is not possible to compare the impact of an increase in forest area monitoring frequency on the accuracy of estimates of forest area change, and thereby test the related hypothesis in Section 4.2. However, it is possible to infer the impact of REDD+ Readiness and other initiatives to improve national forest monitoring capacity. Before these were launched, evidence 
in FAO's Forest Resources Assessments for 1980 to 2005 [38,80-82] shows that four countries only had two surveys since 1970 and for three of them the gap between surveys was 15-20 years. Ghana had no surveys at all. For the remaining countries, the gap was generally 5 to 15 years (Figure 5a).

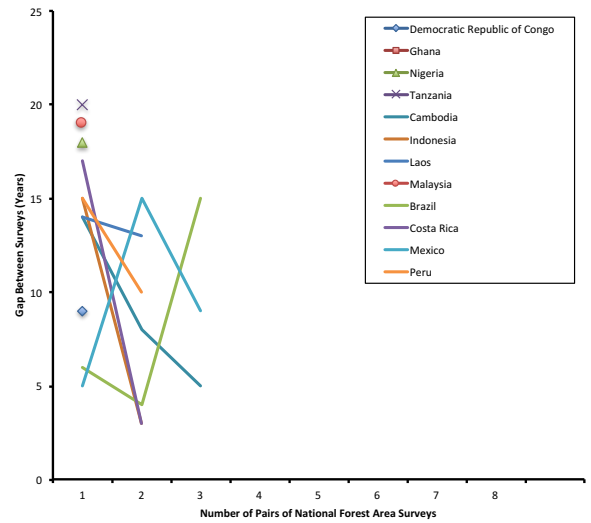

a. All countries before REDD Readiness

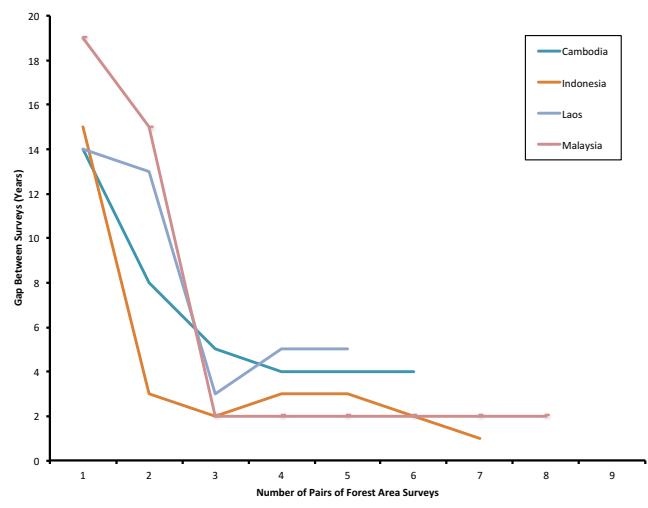

c. Asia

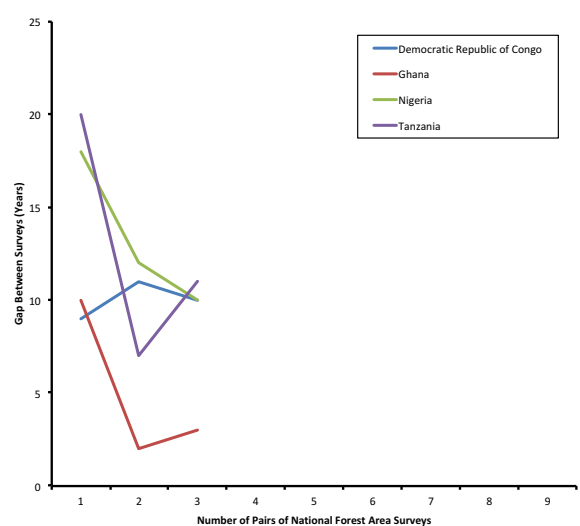

b. Africa

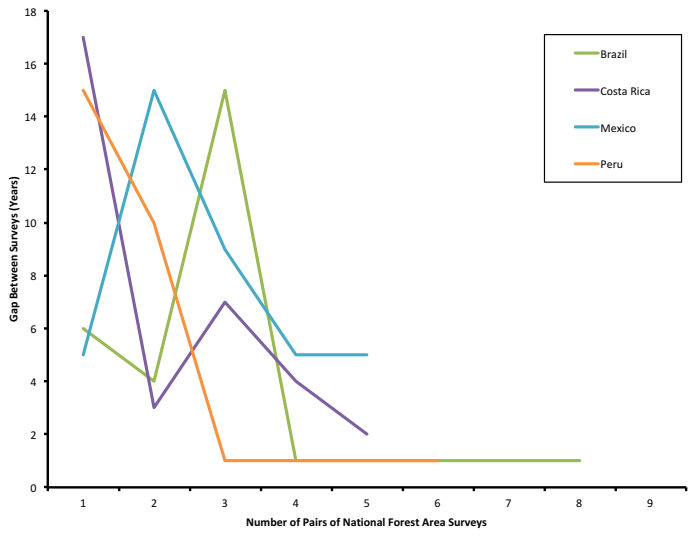

d. Latin America

Figure 5. Frequencies of national forest area surveys in twelve tropical countries, showing the number of years between successive surveys: (a) before REDD+ Readiness [38,80-82]; and afterwards in (b) Africa, (c) Asia and (d) Latin America [66-77].

The FREL reports show that REDD+ Readiness has greatly increased survey frequency for all countries except Brazil (whose monitoring capacity has long been impressive). In Asia and Latin America, there have been up to 8 pairs of surveys per country since 2005 and in all countries the latest frequency is 5 years or less, with a mean of 2.3 years for Latin America and 3.0 years for Asia (Figure 5c,d). In Africa the mean frequency has only fallen to 8.3 years: Ghana has cut its frequency to 3 years, but Democratic Republic of the Congo and Nigeria have only had one pair of surveys and their frequency is still 10 years, while that for Tanzania is 11 years (Figure 5b).

2. Not identifying forest degradation and regeneration. Accurately quantifying the carbon lost when forest is degraded by logging and the carbon gained through regrowth in logged forest, and by enhanced growth in mature forest, requires frequent measurement by forest inventories and satellites. All NGGIs and FREL reports have vertical temporal uncertainties. Only one FREL report (for Brazil) refers to satellite data being used to monitor degradation. All FREL reports show greater use of 
inventory data than the NGGIs (Table S9) but none states how frequently these data are collected. This helps to explain the vertical underspecification described in Section 5.3.4.

\subsection{Fingerprinting Uncertainties in National Submissions to the UNFCCC}

\subsubsection{Constructing the Uncertainty Fingerprints}

Each of the sources of uncertainty described in Sections 5.2-5.4 can constrain, stretch or compress the magnitudes of estimates in different ways. Combining all the uncertainties for an estimate in its Uncertainty Fingerprint allows evaluation of the overall uncertainty of estimates for multiple countries, as in the Global Stocktake, and comparisons between the uncertainties of different estimates for the same country, as in REDD+ monitoring, and different sets of estimates for multiple countries, such as those made for the Global Stocktake by the UNFCCC and IPCC. The fingerprints for all twelve NGGI and FREL estimates are shown graphically in Figure 6 and in shorthand form in Table S11. All assume the presence of random errors, and of residual systematic errors ("sy") when no specific systematic errors are listed.

\begin{tabular}{|c|c|c|c|c|c|c|c|c|c|c|c|}
\hline & \multicolumn{5}{|c|}{ Conceptualization } & \multicolumn{5}{|c|}{ Measurement } & \multirow{2}{*}{\begin{tabular}{|l|} 
Score \\
\end{tabular}} \\
\hline & Terminologica & Underspecification & Understructur & ization & Proxy & Random errors & Systematic errors & Scalar & Subjective & Temporal & \\
\hline Laos & $t_{\mathrm{sp}}, \mathrm{t}_{\mathrm{v}}$ & usp $_{\text {spa }}$, usp spdg $_{\text {, }}$ usp & ust pool, ust $_{\text {col }}$ & ustic & $\mathrm{pr}_{\mathrm{log}}$ & $\mathrm{r}$ & $s y_{s p}, s y_{v}$ & - & - & $T_{s p} \quad T_{v}$ & 14 \\
\hline Mexico & $t_{s p}, t_{v}$ & usp $_{\text {spa }}$, usp $_{\text {spdg }}$, usp $_{v}$ & ust $_{\text {pool, }}$, ust $_{\text {ecol }}$ & ust $_{1 c}$ & $\mathrm{pr}_{\log }$ & $r$ & $s y_{s p}$ & - & - & $\mathrm{T}_{\mathrm{sp}}$ & 13 \\
\hline Malaysia & $t_{s p}, t_{v}$ & usp $_{\text {spa }}$, usp $_{\text {spdg }}$ & ust $_{\text {pool, }}$ ust $_{\text {ecol }}$ & ust $_{1 \mathrm{c}}$ & $\mathrm{pr}_{\log }$ & $r$ & $\mathrm{sy}_{\mathrm{sp}}, \mathrm{sy}_{\mathrm{v}}$ & - & - & $\begin{array}{|ll|}T_{\mathrm{sp}} & \mathrm{T}_{\mathrm{v}} \\
\end{array}$ & 13 \\
\hline \begin{tabular}{|l|} 
Peru \\
\end{tabular} & $t_{s p}, t_{v}$ & usp $_{\text {spa }}$, usp $_{\text {spdg }}$ & ust $_{\text {pool, }}$ ust $_{\text {ecol }}$ & ust $_{\text {ic }}$ & $\mathrm{pr}_{\mathrm{log}}$ & $r$ & $\mathrm{sy}_{\mathrm{v}}, \mathrm{sy}_{\mathrm{vis}}$ & - & - & $T_{\mathrm{sp}}$ & 13 \\
\hline Nigeria & $t_{s p}$ & usp $_{\text {spa }}$, usp $_{\text {spdg, }}$ usp $p_{v}$ & ust $_{\text {pool, }}$, ustecol & ust $t_{c}$ & - & $r$ & $s y_{s p}, s y_{v}$ & - & - & \begin{tabular}{|ll}
$T_{\mathrm{sp}}$ & $\mathrm{T}_{\mathrm{v}}$ \\
\end{tabular} & 12 \\
\hline Cambodia & $t_{s p}$ & usp $_{\text {spa }}$, usp $_{\text {spdg }}$, usp $_{v}$ & ust $_{\text {pool, }}$ ust $_{\text {ecol }}$ & ust $_{\text {ic }}$ & - & $r$ & $\mathrm{sy}_{\mathrm{sp}}, \mathrm{sy}_{\mathrm{v}}$ & - & - & $\mathrm{T}_{\mathrm{sp}}$ & 12 \\
\hline DR Congo & $t_{\mathrm{sp}}$ & usp $_{\text {spa }}$, usp $_{\text {spdg }}$, usp v & ust $_{\text {pool }}$ & ust $_{\text {ic }}$ & - & $r$ & $s y_{s p}, s y_{v}$ & - & - & $\mathrm{T}_{\mathrm{sp}}$ & 11 \\
\hline Tanzania & $t_{\mathrm{sp}}$ & usp $_{\text {spa }}$, usp $_{\text {spdg }}$, usp $_{v}$ & ust $_{\text {ecol }}$ & ust $_{c}$ & - & $r$ & $\mathrm{sy}_{\mathrm{sp}}, \mathrm{sy}_{\mathrm{v}}$ & - & - & $\mathrm{T}_{\mathrm{sp}}$ & 11 \\
\hline Costa Rica & $t_{s p}$ & usp $_{\text {spa }}$, usp $_{\text {spdg }}$, usp $_{v}$ & ust $_{\text {pool }}$, ust ecol $_{\text {el }}$ & ust $t_{\text {c }}$ & - & $r$ & $\mathrm{sy}_{\mathrm{vis}}$ & - & - & $T_{s p}$ & 11 \\
\hline Indonesia & $t_{s p}$ & usp $_{\text {spa }}$, usp $_{\text {spdg }}$, usp $_{v}$ & ust $_{\text {pool }}$ & ust $_{\text {ic }}$ & - & $r$ & $s y_{s p}, s y_{v}$ & - & - & $\mathrm{T}_{\mathrm{sp}}$ & 11 \\
\hline Ghana & $t_{\text {sp }}$ & $\mathrm{usp}_{\mathrm{spa}}, \mathrm{usp}_{\mathrm{spdg}}, \mathrm{usp} \mathrm{v}_{\mathrm{v}}$ & ustecol & $u^{u t_{c}}$ & - & $\mathrm{r}$ & sy $y_{s p}$ & - & - & $T_{\mathrm{sp}} \quad \mathrm{T}_{\mathrm{v}}$ & 10 \\
\hline Brazil & $t_{\mathrm{sp}}$ & $\mathrm{usp}_{\mathrm{spa}}, \mathrm{usp}_{\mathrm{spdq}}, \mathrm{usp}_{\mathrm{v}}$ & & ust $_{\mathrm{cc}}$ & - & $\mathrm{r}$ & sy $_{\text {vis }}$ & - & - & $\mathrm{T}_{\mathrm{v}}$ & 8 \\
\hline
\end{tabular}

a. National Greenhouse Gas Inventories

\begin{tabular}{|c|c|c|c|c|c|c|c|c|c|c|}
\hline & \multicolumn{4}{|c|}{ Conceptualization } & \multicolumn{5}{|c|}{ Measurement } & \multirow{2}{*}{ Score } \\
\hline & Terminological & Underspecification & Understructuralizatio & Proxy & Random errors & Systematic errors & Scalar & Subjective & Temporal & \\
\hline Costa Rica & $t_{s p}$ & usp $_{\text {spa }}$, usp $_{\text {spdq }}, \mathrm{usp}_{\mathrm{v}}$ & ust $_{\text {pool }} \quad$ ust $_{\text {c }}$ & - & r & sy & - & - & $\begin{array}{ll}T_{s p} & T_{v} \\
\end{array}$ & 10 \\
\hline Laos & $\mathrm{t}_{\mathrm{v}}$ & usp $_{\text {spdg }}$ & ust & $\mathrm{pr}_{\log }$ & $\mathrm{r}$ & sy vis & - & - & 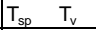 & 9 \\
\hline Cambodia & - & usp $_{\text {spa }}$, usp $_{\text {spdg }}, \mathrm{usp}_{\mathrm{v}}$ & ust $_{\text {pool }}$ & - & $\mathrm{r}$ & $\mathrm{sy}_{\text {vis }}$ & - & - & $\begin{array}{ll}T_{s p} & T_{v} \\
\end{array}$ & 9 \\
\hline Indonesia & $t_{v}$ & usp $_{\text {spdg }}$, usp & ust ${ }_{\text {pool }}$ & $\mathrm{pr}_{\log }$ & $r$ & sy $_{\text {vis }}$ & - & - & $\mathrm{T}_{\mathrm{v}}$ & 8 \\
\hline Ghana & $t_{v}$ & usp $_{\text {spa }} \quad$ usp $_{\mathrm{v}}$ & - & $\mathrm{pr}_{\log }$ & $r$ & sy & - & - & $\begin{array}{ll}T_{s p} & T_{v} \\
\end{array}$ & 8 \\
\hline Malaysia & - & $\mathrm{usp}_{\mathrm{spa}}, \mathrm{usp}_{\mathrm{spdg}}, \mathrm{usp} \mathrm{v}_{\mathrm{v}}$ & ust & - & $\mathrm{r}$ & sy & - & - & $\mathrm{T}_{\mathrm{v}}$ & 8 \\
\hline Mexico & - & - & ust $_{\text {pool }}$ & - & $\mathrm{r}$ & sy $_{\text {vis }}$ & - & - & $\begin{array}{ll}T_{s p} & T_{v} \\
\end{array}$ & 6 \\
\hline$D R$ Congo & - & - & ust $_{\text {pool }}$ & - & $\mathrm{r}$ & sy $_{\text {vis }}$ & - & - & $T_{s p}$ & 5 \\
\hline Nigeria & - & - & ust & - & $r$ & $\mathrm{sy}_{\text {vis }}$ & - & - & $T_{s p}$ & 5 \\
\hline Tanzania & - & - & ust $_{\text {pool }}$ & - & $r$ & $\mathrm{sy}_{\text {vis }}$ & - & - & \begin{tabular}{|ll}
$T_{s p}$ & $T_{v}$ \\
\end{tabular} & 5 \\
\hline Brazil & - & - & ust $_{\text {pool }}$ & - & $r$ & $\mathrm{sy}_{\text {vis }}$ & - & - & $T_{v}$ & 5 \\
\hline Peru & - & - & ust $t_{\text {pool }}$ & - & $\mathrm{r}$ & sy vis & - & - & $\mathrm{T}_{\mathrm{v}}$ & 5 \\
\hline
\end{tabular}

b. Forest Reference Emission Level reports

NB. $t_{s p}$, spatial terminological difficulties; $t_{v}$, vertical terminological difficulties; $u_{s p}$ spa, spatial area underspecification;

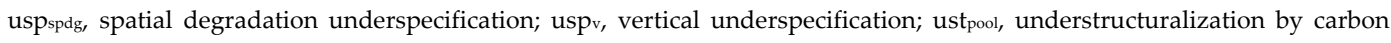
pools; ustecol, understructuralization by ecosystem type, ustic, understructuralization by land cover change; sysp, spatial systematic errors; syv, vertical systematic errors; syvis, systematic errors due to use of visual image analysis; sy, general systematic errors; $\mathrm{r}$, random errors; $\mathrm{T}_{\mathrm{sp}}$, spatial temporal uncertainties; $\mathrm{T}_{\mathrm{v}}$, vertical temporal uncertainties. The Uncertainty Score is the total number of uncertainties in each fingerprint.

Figure 6. Uncertainty Fingerprints for twelve tropical countries of estimates in (a) National Greenhouse Gas Inventories; and (b) Forest Reference Emission Level reports (the partial group of countries in italics only report emissions from deforestation) [54-77].

Comparing the NGGI and FREL estimates is challenging since they are not homogeneous in the reporting categories for which they provide estimates (see Section 5.1). Each Uncertainty Fingerprint refers to the total reporting variable which is the focus of each national estimate and is shown in bold in Tables S1 and S3. For the NGGIs, Uncertainty Fingerprints are constructed for estimates of 
Net LUCF $\mathrm{CO}_{2}$ Emissions for Brazil, Cambodia, Democratic Republic of the Congo, Indonesia, Laos, Malaysia, Mexico, Nigeria and Peru; Total LUCF CO $\mathrm{C}_{2}$ Emissions for Costa Rica and Tanzania; and Net LUCF Emissions of All Greenhouse Gases for Ghana. For the FREL reports, the fingerprints refer to estimates of: Total Forest $\mathrm{CO}_{2}$ Emissions for Indonesia; Gross Deforestation $\mathrm{CO}_{2}$ Emissions for Brazil, Democratic Republic of the Congo, Mexico, Nigeria, Peru and Tanzania; and Net Forest $\mathrm{CO}_{2}$ Emissions for Cambodia, Costa Rica, Ghana, Laos and Malaysia. These correspond to each country's preferred Forest Reference Emission Level.

\subsubsection{Comparing Uncertainty Fingerprints}

Three comparisons of the Uncertainty Fingerprints of these sets of estimates, and sub-sets of them, are highlighted here:

1. The Uncertainty Fingerprints of one set of estimates. The NGGI estimates are consistent in having high uncertainties, with all but Brazil having an Uncertainty Score (total number of uncertainties) between 10 and 14 (Figure 6a). Spatial terminological difficulties $\left(t_{\mathrm{sp}}\right)$, spatial and spatial degradation underspecification ( usp $_{\mathrm{spa}}, \mathrm{usp}_{\mathrm{spdg}}$ ), vertical underspecification $\left(\mathrm{usp}_{\mathrm{v}}\right)$, understructuralization by carbon pools (ust $\mathrm{pool}_{\text {pol }}$, ecosystem types (ust ecol ) and land cover change (ust $\mathrm{lc}_{\mathrm{c}}$ ), spatial and vertical systematic errors $\left(\mathrm{sy}_{\mathrm{sp}}, \mathrm{sy}_{\mathrm{v}}\right)$, and spatial and vertical temporal uncertainties $\left(\mathrm{T}_{\mathrm{sp}}, \mathrm{T}_{\mathrm{v}}\right)$ are all common. The most uncertain estimates have vertical terminological difficulties $\left(t_{\mathrm{v}}\right)$ and proxy uncertainties $\left(\mathrm{pr}_{\mathrm{log}}\right)$ too. The least uncertain estimate, for Brazil, lacks understructuralization by carbon pools (ust $_{\text {pool }}$ ) and ecosystem types (ust $\mathrm{ecol}_{\text {) }}$, spatial systematic errors $\left(\mathrm{sy}_{\mathrm{sp}}\right)$, vertical systematic errors $\left(\mathrm{sy}_{\mathrm{v}}\right)$ and spatial temporal uncertainties $\left(\mathrm{T}_{\mathrm{sp}}\right)$.

The high uncertainty of the NGGIs, and their inconsistent incompleteness in reporting total categories and forest flux estimates, shows that it will be difficult to construct meaningful global estimates of net forest $\mathrm{CO}_{2}$ emissions in the Global Stocktake.

In contrast, the Uncertainty Fingerprints for the FREL reports are all moderately uncertain, with Uncertainty Scores between 5 and 10 (Figure 6b). They generally lack understructuralization by ecosystem types ( ust $_{\text {ecol }}$ ), spatial terminological difficulties $\left(t_{\mathrm{sp}}\right)$, spatial systematic errors $\left(\mathrm{sy}_{\mathrm{sp}}\right)$ and vertical systematic errors $\left(\mathrm{sy}_{\mathrm{v}}\right)$. They are less internally consistent than the NGGI fingerprints, since six countries (Brazil, Democratic Republic of the Congo, Mexico, Nigeria, Peru and Tanzania-named in italics in Figure 6b), which we call the partial group, focus on just reporting gross deforestation emissions and so have no underspecification or proxy uncertainties. This introduces bias into the distribution of Uncertainty Scores for the FREL reports. The uncertainties for the partial group are comparable with each other, with Uncertainty Scores of only 5 or 6 , as are those of the remaining comprehensive group, whose Uncertainty Scores range from 8 to 10.

2. The Uncertainty Fingerprints of two sets of estimates. The FREL reports are less uncertain than the NGGIs: the mean Uncertainty Score per country is 11.6 in the NGGIs, but only 6.9 in the FREL reports, out of a total of 17 potential sources (of which 9 are for conceptualization and 8 for measurement) (Tables 7 and S12). If the uncertainties of the NGGI estimates are inflated by a lack of information on data sources, the actual uncertainties of national estimates submitted to the Global Stocktake may be lower than those evaluated here. To address this issue further we also compared the fingerprints of two subsets of estimates:

Table 7. Mean Uncertainty Scores for the National Greenhouse Gas Inventories (NGGIs) and Forest Reference Emission Level (FREL) reports of the comprehensive and partial groups of countries, and the group of 8 countries in Table $5 b$ [54-77].

\begin{tabular}{lcc}
\hline & NGGIs & FREL Reports \\
\hline Comprehensive Group & 11.8 & 8.7 \\
Partial Group & 11.3 & 5.2 \\
All 12 Countries & $\mathbf{1 1 . 6}$ & $\mathbf{6 . 9}$ \\
\hline Group of 8 countries (Table 5b) & 8.6 & 5.3 \\
\hline
\end{tabular}


a. Estimates for multiple forest carbon fluxes. To simulate a possible comparison of the uncertainties of sets of estimates by governments and scientists assessed by the Global Stocktake we compared the fingerprints of the NGGI and FREL estimates of the comprehensive group of countries, which includes Cambodia, Costa Rica, Ghana, Indonesia, Laos and Malaysia. The comprehensive group of FREL estimates has the lower uncertainty expected of scientific estimates, and is most comparable with the NGGI estimates since it generally tries to estimate more than one flux (in their FREL reports, Indonesia estimates aggregated emissions and Costa Rica aggregated removals). The comprehensive group of NGGI estimates is representative of all the NGGI estimates, as its mean Uncertainty Score (11.8) is similar to the overall NGGI mean of 11.6 (Table 7).

It was not practical to compare aggregate estimates of more than one forest carbon flux for both sets of estimates (see Section 5.1). However, the comprehensive group of NGGI estimates contains most major sources of uncertainty except for spatial underspecification (usp $\mathrm{sp}_{\mathrm{sp}}$ ) and its Uncertainty Scores range from 10 to 14 (Figure 7a). In contrast, the comprehensive group of FREL estimates, with Uncertainty Scores of 8-10, has hardly any spatial terminological difficulties $\left(t_{\mathrm{sp}}\right)$ and spatial systematic errors ( $\mathrm{sy}_{\mathrm{sp}}$ ), which tends to reduce gross fluxes, and understructuralization by ecosystem types (ust ecol$)$, which tends to raise gross fluxes. Vertical systematic errors $\left(\mathrm{sy}_{\mathrm{v}}\right)$ are absent (Figure $\left.7 \mathrm{~b}\right)$.

\begin{tabular}{|c|c|c|c|c|c|c|c|c|c|c|c|}
\hline & \multicolumn{5}{|c|}{ Conceptualization } & \multicolumn{5}{|c|}{ Measurement } & \multirow[t]{2}{*}{ Score } \\
\hline & Terminological & Underspecification & Understructur & lization & Proxy & Random errors & Systematic errors & Scalar & Subjective & Temporal & \\
\hline Laos & $t_{\mathrm{sp}}, \mathrm{t}_{\mathrm{v}}$ & 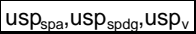 & ust $_{\text {pool }}$, ust $_{\text {ecol }}$ & ust $_{c}$ & $\mathrm{pr}_{\log }$ & \begin{tabular}{|l|l}
$r$ & \\
\end{tabular} & sy $_{\text {sp }}$, sy $_{\mathrm{v}}$ & - & \begin{tabular}{|l|}
- \\
\end{tabular} & $\begin{array}{ll}T_{\mathrm{sp}} & \mathrm{T}_{\mathrm{v}} \\
\end{array}$ & 14 \\
\hline Malaysia & $t_{s p}, t_{v}$ & usp $_{\text {spa }}$, usp $_{\text {spdg }}$ & ust $_{\text {pool, }}$, ust $_{\text {ecol }}$ & ust tic $_{\text {c }}$ & $\mathrm{pr}_{\log }$ & $r$ & sy $_{\text {sp }}$, sy $_{\mathrm{v}}$ & - & - & $\mathrm{T}_{\mathrm{sp}}$ & 13 \\
\hline Cambodia & $t_{\mathrm{sp}}$ & $\mathrm{usp}_{\mathrm{spa}}, \mathrm{usp}_{\mathrm{spdg}}, \mathrm{usp}_{\mathrm{v}}$ & ust $_{\text {pool, }}$ ust $_{\text {ecol }}$ & ust $_{\text {ic }}$ & - & $r$ & sy $_{\text {sp }}$, sy $_{\mathrm{v}}$ & - & - & $T_{\mathrm{sp}}$ & 12 \\
\hline Costa Rica & $t_{s p}$ & $\mathrm{usp}_{\mathrm{spa}}, \mathrm{usp}_{\mathrm{spdg}}, \mathrm{usp}_{\mathrm{v}}$ & ust $_{\text {pool }}$, ust $_{\text {ecol }}$ & ust $_{\mathrm{ic}}$ & - & $r$ & \begin{tabular}{|r|} 
sy $_{\text {vis }}$ \\
\end{tabular} & - & - & $\mathrm{T}_{\mathrm{sp}}$ & 11 \\
\hline Indonesia & $t_{s p}$ & usp $_{\text {spa }}$, usp $_{\text {spdg }}$, usp $_{v}$ & ust $_{\text {pool }}$ & ust $_{\text {ic }}$ & - & $r$ & $\mathrm{sy}_{\mathrm{sp}}, \mathrm{sy}_{\mathrm{v}}$ & - & - & $T_{s p}$ & 11 \\
\hline Ghana & $t_{s p}$ & $\mathrm{usp}_{\text {spa }}, \mathrm{usp}_{\mathrm{spdg}}, \mathrm{usp}_{\mathrm{v}}$ & ust $_{\text {ecol }}$ & ust $_{1 c}$ & - & $r$ & sy $\mathrm{sp}_{\mathrm{sp}}$ & - & - & $\mathrm{T}_{\mathrm{sp}}$ & 10 \\
\hline
\end{tabular}

a. National Greenhouse Gas Inventories

\begin{tabular}{|c|c|c|c|c|c|c|c|c|c|c|}
\hline & \multicolumn{4}{|c|}{ Conceptualization } & \multicolumn{5}{|c|}{\begin{tabular}{|l|} 
Measurement \\
\end{tabular}} & \multirow[t]{2}{*}{ Score } \\
\hline & Terminological & Underspecification & Understructuralization & Proxy & Random errors & Systematic errors & Scalar & Subjective & Temporal & \\
\hline Costa Rica & $t_{\mathrm{sp}}$ & usp $_{\text {spa }}$, usp $_{\text {spdg }}$, usp $_{v}$ & ust $_{\text {pool }} \quad$ ust $_{c}$ & - & $r$ & sy & - & 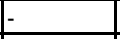 & $\begin{array}{|ll|}T_{s p} & T_{v} \\
\end{array}$ & 10 \\
\hline \begin{tabular}{|l|l} 
Laos & \\
\end{tabular} & $t_{v}$ & $u_{\mathrm{usp}}$ spdg & ust pool $_{\text {pal }}$ & $\mathrm{pr}_{\log }$ & $r$ & sy vis & - & - & $\begin{array}{ll}T_{\text {sp }} & \mathrm{T}_{\mathrm{v}} \\
\end{array}$ & 9 \\
\hline Cambodia & - & $\mathrm{usp}_{\mathrm{spa}}, \mathrm{usp}_{\mathrm{spdg}}, \mathrm{usp}_{\mathrm{v}}$ & ust $_{\text {pool }}$ & - & $r$ & sy $_{\text {vis }}$ & - & - & \begin{tabular}{|ll}
$T_{\text {sp }}$ & $\mathrm{T}_{\mathrm{v}}$ \\
\end{tabular} & 9 \\
\hline Indonesia & $t_{v}$ & usp $_{\text {spdg}}$, usp $_{\mathrm{v}}$ & ust $_{\text {pool }}$ & $\mathrm{pr}_{\log }$ & $r$ & sy $_{\text {vis }}$ & - & - & $\mathrm{T}_{\mathrm{v}}$ & 8 \\
\hline Ghana & $t_{v}$ & $\begin{array}{ll}\text { usp }_{\text {spa }}, & \text { usp }_{v} \\
\end{array}$ & - & $\mathrm{pr}_{\text {log }}$ & $r$ & sy & - & - & \begin{tabular}{|ll}
$\mathrm{T}_{\mathrm{sp}}$ & $\mathrm{T}_{\mathrm{v}}$ \\
\end{tabular} & 8 \\
\hline Malaysia & - & usp $_{\text {spa }}$, usp $_{\text {spdg }}$, usp $_{v}$ & ust $_{\text {pool }}$ & - & $r$ & sy & - & - & $\mathrm{T}_{\mathrm{v}}$ & 8 \\
\hline
\end{tabular}

b. Forest Reference Emission Level reports

Figure 7. Uncertainty Fingerprints for the comprehensive group of six tropical countries of estimates in (a) National Greenhouse Gas Inventories; (b) Forest Reference Emission Level reports [55,57-61,67,69-73].

b. Estimates for gross deforestation emissions only. A comparison of uncertainties associated with the estimates for eight countries of deforestation emissions in the NGGIs $\left(1,302 \mathrm{Mt} \mathrm{CO}_{2} \mathrm{a}^{-1}\right)$ and FREL reports ( $585 \mathrm{Mt} \mathrm{CO}_{2} \mathrm{a}^{-1}$ ) (Table $5 \mathrm{~b}$ ) can be used to simulate the comparison of the uncertainties of trends in estimates of deforestation emissions submitted to REDD+. In this artificial comparison, the NGGI estimates represent the first period and the FREL estimates the second period when emissions have fallen. The original fingerprints (Figure 6) are replaced by evaluations only for estimates of gross deforestation rates (Figure 8).

Both sets of estimates are less uncertain than the corresponding estimates for all fluxes (Figure 6), but the FREL estimates (with a mean Uncertainty Score of 5.3) are less uncertain than the NGGI estimates (with a score of 8.6) (Table 7). The FREL estimates (Figure 8b) have fewer cases of spatial terminological difficulties $\left(t_{\mathrm{sp}}\right)$, understructuralization by ecosystem types ( $\left.u_{\mathrm{s}} \mathrm{t}_{\mathrm{ecol}}\right)$, understructuralization by land cover change $\left(u_{s t} t_{l c}\right)$, spatial systematic errors $\left(s y_{s p}\right)$ and vertical systematic errors $\left(s_{v}\right)$ than the NGGI estimates (Figure 8a) but more systematic errors linked to visual analysis of satellite images $\left(\mathrm{sy}_{\mathrm{vis}}\right)$. These differences in understructuralization would favour the higher net emissions in the NGGI estimates (Table 5b), consolidating the effect of apparently higher deforestation rates, but differences in 
spatial systematic errors $\left(\mathrm{sy}_{\mathrm{sp}}\right.$ ) would counter this. The FREL estimates have fewer spatial temporal uncertainties but both sets of estimates are heavily understructuralized by carbon pools (ust pool $_{\text {). }}$ As there is no overall predictable bias resulting from the combinations of uncertainties in the two sets of estimates, differences in deforestation emissions seem to be influenced mainly by differences in deforestation rates.

\begin{tabular}{|c|c|c|c|c|c|c|c|c|c|c|c|}
\hline & \multicolumn{5}{|c|}{ Conceptualization } & \multicolumn{5}{|c|}{ Measurement } & \multirow{2}{*}{\begin{tabular}{|l|} 
Score \\
\end{tabular}} \\
\hline & Terminological & Underspecification & Understructu & lization & Proxy & Random errors & Systematic errors & Scalar & Subjective & Temporal & \\
\hline Nigeria & $t_{s p}$ & - & ust $_{\text {pool }}$, ust ecol $_{1}$ & ust $_{\text {c }}$ & - & $\mathrm{r}$ & $\mathrm{sy}_{\mathrm{sp}}, \mathrm{sy}_{\mathrm{v}}$ & - & - & $\begin{array}{ll}\mathrm{T}_{\mathrm{sp}} & \mathrm{T}_{\mathrm{v}} \\
\end{array}$ & 9 \\
\hline Cambodia & $t_{s p}$ & - & ust $_{\text {pool }}$, ust $_{\text {ecol }}$ & ust $_{\mathrm{c}}$ & - & $r$ & sy ${ }_{s p}, s_{v}$ & - & - & $T_{\text {sp }}$ & 9 \\
\hline Laos & $t_{\mathrm{sp}}$ & - & ust $_{\text {pool }}$, ust $_{\text {ecol }}$ & ust $_{\text {c }}$ & - & $r$ & $\mathrm{sy}_{\mathrm{sp}}, \mathrm{sy}_{\mathrm{v}}$ & - & - & $T_{\text {sp }}$ & 9 \\
\hline Malaysia & $t_{\mathrm{sp}}$ & - & ust $_{\text {pool }}$, ust $_{\text {ecol }}$ & ust $_{\mathrm{c}}$ & - & $r$ & sy $\mathrm{sp}_{\mathrm{sp}}, \mathrm{sy}_{\mathrm{v}}$ & - & - & $\begin{array}{ll}\mathrm{T}_{\mathrm{sp}} & \mathrm{T}_{\mathrm{v}} \\
\end{array}$ & 9 \\
\hline Peru & $t_{s p}$ & - & ust $_{\text {pool }}$, ust $_{\text {ecol }}$ & ust $_{\text {c }}$ & - & $r$ & $\mathrm{sy}_{\mathrm{v}}, \mathrm{sy}_{\mathrm{vis}}$ & - & - & $T_{s p}$ & 9 \\
\hline Tanzania & $t_{s p}$ & - & ust $_{\text {ecol }}$ & ust $_{c}$ & - & $r$ & $\mathrm{sy}_{\mathrm{sp}}, \mathrm{sy}_{\mathrm{v}}$ & - & - & $\begin{array}{ll}T_{\mathrm{sp}} & \mathrm{T}_{\mathrm{v}} \\
\end{array}$ & 8 \\
\hline Indonesia & $t_{\text {sp }}$ & - & ust $_{\text {pool }}$ & ust $_{\mathrm{c}}$ & - & $r$ & $\mathrm{sy}_{\mathrm{sp}}, \mathrm{sy}_{\mathrm{v}}$ & - & - & $T_{s p}$ & 8 \\
\hline Mexico & $t_{s p}$ & - & ust $_{\text {pool }}$, ust $_{\text {ecol }}$ & ust $_{\text {c }}$ & - & $r$ & $\mathrm{sy}_{\mathrm{sp}}$ & - & - & $\mathrm{T}_{\mathrm{sp}}$ & 8 \\
\hline
\end{tabular}

a. National Greenhouse Gas Inventories

\begin{tabular}{|c|c|c|c|c|c|c|c|c|c|c|}
\hline & \multicolumn{4}{|c|}{\begin{tabular}{|c|} 
Conceptualization \\
\end{tabular}} & \multicolumn{5}{|c|}{\begin{tabular}{|c|} 
Measurement \\
\end{tabular}} & \multirow{2}{*}{ Score } \\
\hline & Terminological & Underspecification & Understructuralization & Proxy & Random errors & Systematic errors & Scalar & Subjective & Temporal & \\
\hline Cambodia & 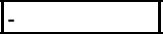 & - & ust $_{\text {pool }} \quad$ ust $_{c}$ & - & \begin{tabular}{|l|l|l}
$\mathrm{r}$ &
\end{tabular} & sy $_{\text {vis }}$ & - & - & \begin{tabular}{ll|}
$T_{\mathrm{sp}}$ & $\mathrm{T}_{\mathrm{v}}$ \\
\end{tabular} & 6 \\
\hline Laos & - & - & ust $_{\text {pool }}$ & - & $r$ & sy $_{\text {vis }}$ & - & - & $\begin{array}{ll}T_{s p} & T_{v} \\
\end{array}$ & 6 \\
\hline Mexico & - & - & ust $_{\text {pool }}$ & - & $\mathrm{r}$ & sy $_{\text {vis }}$ & - & - & \begin{tabular}{|ll}
$T_{s p}$ & $T_{v}$ \\
\end{tabular} & 6 \\
\hline Nigeria & - & - & ust $_{\text {pool }}$ & - & $r$ & sy $_{\text {vis }}$ & - & - & \begin{tabular}{|ll}
$\mathrm{T}_{\mathrm{sp}}$ & $\mathrm{T}_{\mathrm{v}}$ \\
\end{tabular} & 5 \\
\hline Tanzania & - & - & ust $_{\text {pool }}$ & - & $r$ & sy $_{\text {vis }}$ & - & - & \begin{tabular}{|ll}
$\mathrm{T}_{\mathrm{sp}}$ & $\mathrm{T}_{\mathrm{v}}$ \\
\end{tabular} & 5 \\
\hline Malaysia & - & - & ust $_{\text {pool }}$ & - & $r$ & sy & - & - & $\mathrm{T}_{\mathrm{v}}$ & 5 \\
\hline Peru & - & - & ust $_{\text {pool }}$ & - & $r$ & sy $_{\text {vis }}$ & - & - & $T_{v}$ & 5 \\
\hline Indonesia & - & - & ust $_{\text {pool }}$ & - & $r$ & sy $_{\text {vis }}$ & - & - & $T_{v}$ & 4 \\
\hline
\end{tabular}

b. Forest Reference Emission Level reports

Figure 8. Uncertainty Fingerprints for eight tropical countries of estimates of gross deforestation emissions in (a) National Greenhouse Gas Inventories; (b) Forest Reference Emission Level reports (Table 5b) [55,59-65,67,71-77].

\subsubsection{Qualitative Uncertainties Versus Quantitative Uncertainties}

Qualitative (conceptualization) uncertainties make an important contribution to overall uncertainty, accounting for $60 \%$ and $47 \%$, respectively, of the total Uncertainty Scores of the NGGIs and FREL Reports (Figure 9). This supports the assertion of Van der Sluijs about the limitations of quantitative evaluations of very uncertain phenomena [15]. 


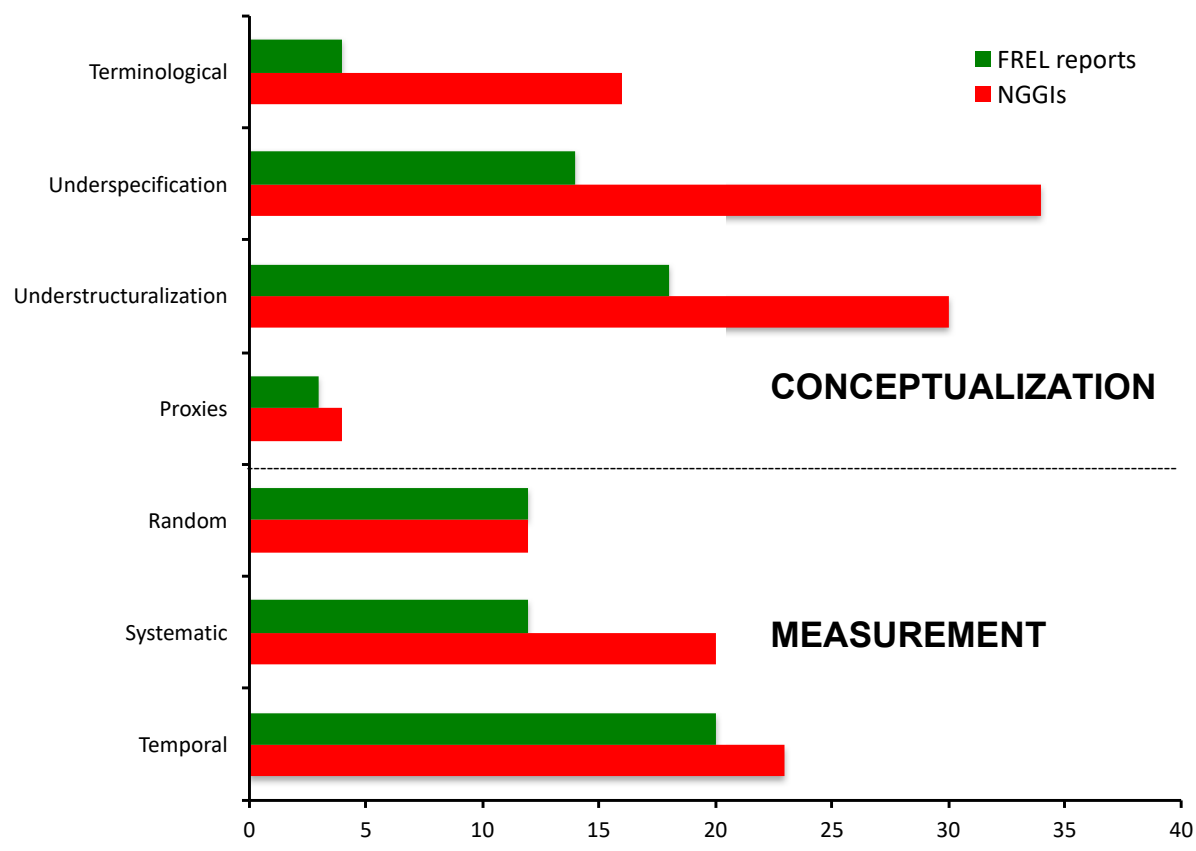

Figure 9. The numbers of conceptualization uncertainties and measurement uncertainties in the Uncertainty Fingerprints for twelve tropical countries of estimates in National Greenhouse Gas Inventories (NGGIs) and Forest Reference Emission Level (FREL) reports [54-77].

\subsubsection{Completeness and Disaggregation}

Completeness and disaggregation rankings, assembled as described in Section 4.4, complement the above evaluations of underspecification and understructuralization. The NGGI and FREL estimates are equally incomplete in reporting the six forest carbon fluxes, i.e., deforestation, reforestation, afforestation, spatial and vertical degradation and (re)growth, both having means of 1.8. The comprehensive group's FREL mean of 2.7 is slightly above its NGGI mean (2.2). Except for Brazil, disaggregation is higher in every country's FREL report (with a mean of 4.7) than in its NGGI (with a mean of 1.5) (Tables 8 and S13).

Table 8. Mean completeness and disaggregation rankings for the National Greenhouse Gas Inventories (NGGIs) and Forest Reference Emission Level (FREL) reports of twelve tropical countries [54-77].

\begin{tabular}{lcc}
\hline & Completeness Ranking & Disaggregation Ranking \\
\hline NGGIs & 2.2 & \\
Comprehensive group & 1.3 & 0.8 \\
Partial group & $\mathbf{1 . 8}$ & 2.2 \\
Overall Mean & & $\mathbf{1 . 5}$ \\
FREL reports & 2.7 & 4.5 \\
Comprehensive group & 1.0 & 4.8 \\
Partial group & $\mathbf{1 . 8}$ & $\mathbf{4 . 7}$ \\
Overall Mean & & \\
\hline
\end{tabular}

NB. These ranking methods are described in Section 4.4.

Trade-offs between sensor resolution and completeness of forest area coverage in the 'pre-wall-to-wall Landsat era', e.g., [83], are not repeated in the FREL reports. Information is lacking to determine if they occur in the NGGIs. However, trade-offs between completeness and disaggregation are apparent in both sets of estimates when national values of completeness and disaggregation are divided between four quadrants in a trade-off box (Figure 10). Ideally, the NGGIs and FREL reports would all have low uncertainty and be in quadrant B with High Completeness and High Disaggregation. Yet just two countries, Ghana and Laos, satisfy this criterion and only for their FREL reports. Trading 
off completeness for disaggregation would be expected for the FREL reports, as these tend to focus on submitting accurate estimates of a few fluxes, and this is visible in quadrant A for nine FREL estimates. In quadrant D, however, the NGGI estimates of Cambodia, Indonesia, Laos, Malaysia and Peru trade-off disaggregation for completeness, as expected for NGGI estimates, many of which focus instead on more comprehensive coverage.

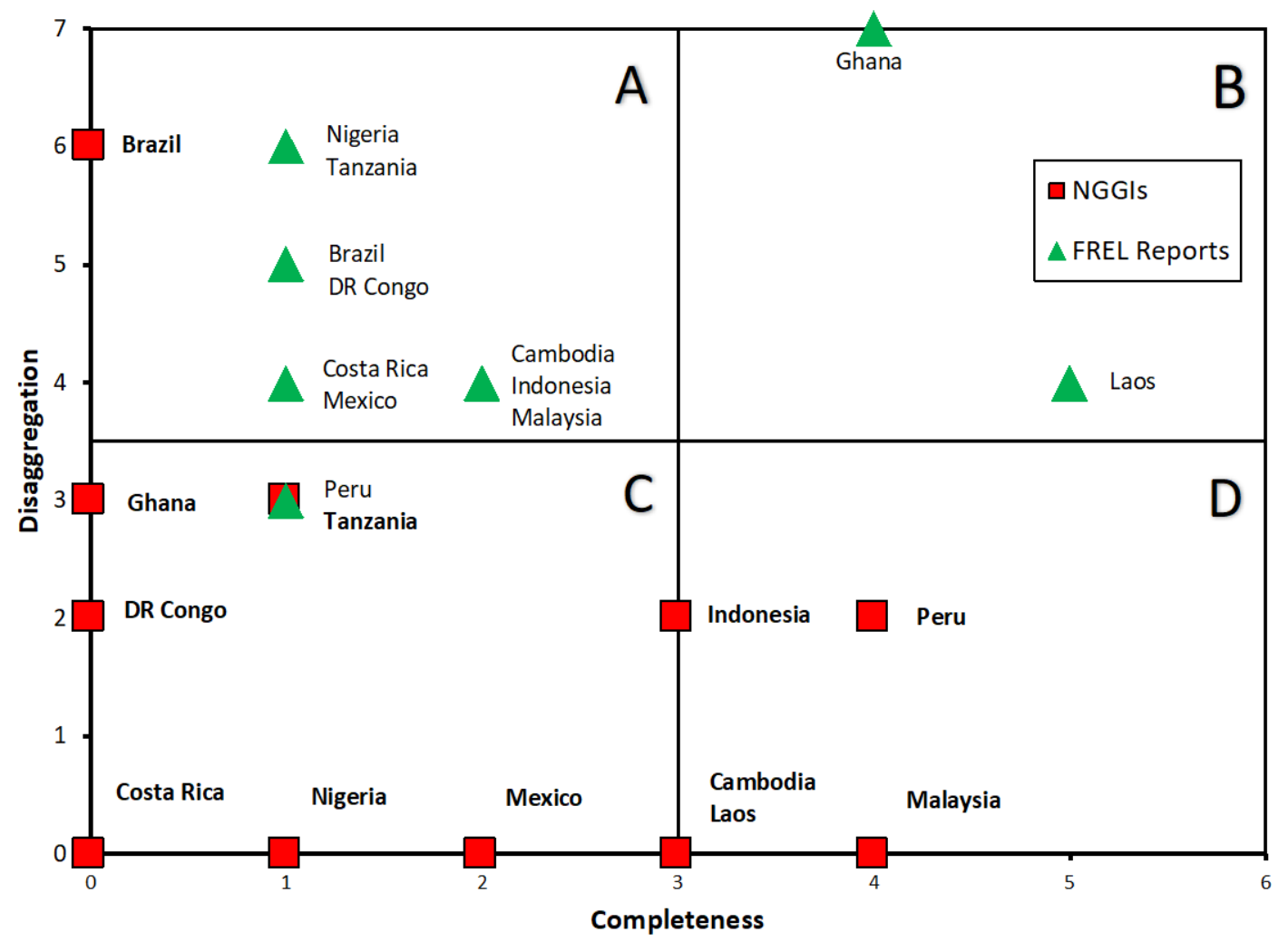

Figure 10. A trade-off box for disaggregation and completeness in estimates in National Greenhouse Gas Inventories (NGGIs) and Forest Reference Emission Level (FREL) reports for twelve tropical countries [54-77].

\subsection{Uncertainty Assessments in the NGGIs and FREL Reports}

Uncertainty assessments are required for NGGIs but only two NGGIs quantify uncertainties associated with estimates of greenhouse gas emissions from the Land Use Change and Forestry sector: Malaysia $\pm 20 \%$ [61] and Laos $\pm 44 \%$ [60], which compare with our high Uncertainty Scores of 13 and 14, respectively. Six FREL reports estimate uncertainties for their Forest Reference Emission Levels though they are not required: Democratic Republic of the Congo $\pm 7 \%$ [68]; Peru $\pm 9 \%$ [76]; Ghana $\pm 11 \%$ [70]; Tanzania $\pm 12 \%$ [77]; Indonesia $\pm 16 \%$ [71]; and Laos $\pm 19 \%$ [72] (Table S14). These errors are below those for the two NGGIs and have lower Uncertainty Scores too (Figure 6b), though the two highest estimates also have high Uncertainty Scores: 8 for Indonesia and 9 for Laos.

\section{Implications for Reducing Uncertainty in National Reports to the UNFCCC}

Since our analysis shows that, despite REDD+ Readiness programmes, uncertainties will still constrain the Global Stocktake and monitoring of REDD+ implementation, further improvements in national MRV capacities are needed. Ranking uncertainties in the FREL reports of the 'comprehensive group' of six countries (Figure 7b), which provide the most optimistic guide to national forest carbon monitoring capacity, identifies five groups of uncertainties which require attention (Table 9): 
Table 9. Priorities for enhancing forest monitoring in tropical countries, based on the frequency of uncertainty categories in the Uncertainty Fingerprints of the Forest Reference Emission Level (FREL) reports of the comprehensive group of six tropical countries (Figure 7b) [67,69-73].

\begin{tabular}{lc}
\hline Uncertainty Category & Frequency \\
\hline Vertical temporal uncertainties & 6 \\
Understructuralization by carbon pools & 5 \\
Spatial degradation underspecification & 5 \\
Vertical underspecification & 5 \\
Spatial underspecification & 4 \\
Understructuralization by land cover change & 4 \\
Spatial temporal uncertainties & 4 \\
Vertical terminological difficulties & 3 \\
Proxies for logging & 3 \\
Systematic errors due to use of visual image analysis & 3 \\
\hline
\end{tabular}

1. Vertical temporal uncertainties are the greatest source of uncertainty, with a score of 6 . They are linked to vertical underspecification (5), mainly of carbon fluxes for logging degradation and regrowth, understructuralization by carbon pools (5) and the use of proxies (3).

No single existing Earth observation method can provide more accurate estimates of $\mathrm{CO}_{2}$ fluxes linked to selective logging, which so far has only been mapped indirectly using medium resolution optical satellite images, e.g., by spotting bare soil on skid trails etc. [84,85]. There is currently no consensus on how to devise better methods [86-88]. Possible solutions include: optical data; and (b) data fusion of optical images, national forest inventory data and LiDAR surveys. National LiDAR surveys may not be operationally feasible for most tropical countries, but MRV centres could make selective use of global LiDAR surveys, e.g., [7]. More frequent national forest inventories are essential too.

2. Spatial degradation underspecification (5) also contributes to uncertainty since it can lead to underestimation of the degradation flux and overestimation of the deforestation flux. Possible solutions include: (a) mapping percentage tree cover by using medium resolution optical images [89]; and (b) using a novel visual method [90] to classify very high $(\leq 1 \mathrm{~m})$ resolution optical images to map tree density. Several government forestry departments in developing countries already use the latter method, so it should be operationally feasible elsewhere.

3. Spatial underspecification (4), mainly of reforestation and afforestation removals, is a critical constraint on the accuracy of estimates of emissions from forest area change. One promising new technology to reduce spatial underspecification for mapping forest fallow is 'stacking', which maps both non-forest and forest in each hectare every year, stores these maps in a geo-referenced 'stack' on a Geographical Information System (GIS), and then automatically compares the presence of forest in a given area with the year when that area was last deforested to identify the age classes of regrowth forest [91]. However, this technology may not be operationally feasible for most tropical countries.

4. Spatial temporal uncertainties (4), understructuralization by land cover change (4) and systematic errors due to the use of visual image analysis (3) are three related sources of uncertainty about deforestation and forestation fluxes. These could be reduced by upgrading visual analysis from hard copy images to digital images, and then switching to semi-automated classification.

5. Vertical terminological difficulties (3) could be removed if the UNFCCC follows the advice of the IPCC [78] and agrees on a common definition of 'forest degradation'.

\section{Conclusions}

Too little research has been carried out into environmental uncertainties, despite several attempts to establish them as a major field of study $[49,50,92,93]$. To counter this neglect, this paper has shown that extending the Uncertainty Assessment Framework (UAF) [20] can identify the sources of global environmental uncertainties in a way that also shows how to reduce them through better use of Earth 
observation technologies. This method also advances conceptualization in the new Earth observation science $[94,95]$ by proposing that Earth observation should integrate sensor features and Earth surface features and have spatial, vertical and temporal dimensions of measurement.

According to the Copernicus vision [16], Earth observation systems should ideally involve a seamless chain from Earth observation data to usable information in the hands of decision-makers [17]. However, this research has found that in two sets of national estimates of forest carbon fluxes submitted by twelve governments to the UN Framework Convention on Climate Change (UNFCCC), the transformation of Earth observation data has been far from ideal and this has led to considerable uncertainties. We have found high Uncertainty Scores of between 10 and 14 for the National Greenhouse Gas Inventories (NGGIs) and moderate scores of 5 to 10 for the Forest Reference Emission Level (FREL) reports. Both greatly exceed the critical threshold of 2 when it is advisable to evaluate uncertainty by standard statistical methods. We have also extended previous research [14] by finding that after REDD+ Readiness schemes, mean forest area mapping frequency has fallen to 2.3 years in Latin America and 3.0 years in Asia, but only to 8.3 years in Africa. All FREL reports are said to base forest area estimates on at least medium resolution satellite data. Yet despite these achievements in increasing national forest area monitoring capacity, our analysis shows that uncertainties about national forest carbon fluxes will still constrain monitoring of the implementation of the UNFCCC's REDD+ mechanism, and monitoring of the implementation of its Paris Agreement in the Global Stocktake, which is due to combine the net emissions of carbon dioxide (and other greenhouse gases) from many countries to compare their collective warming effect with the Paris Agreement goal. Until now, only a limited amount of research has been carried out into the Global Stocktake [96], so our findings contribute to what will hopefully soon be a rapidly evolving literature.

Owing to limited use of Earth observation data, current global environmental uncertainties involve not only measurement constraints that are amenable to conventional statistical analysis but also conceptualization constraints, including incomplete coverage of forest carbon fluxes, and limited disaggregation of fluxes between different ecosystem types and forest carbon pools. This paper has shown that qualitative conceptualization sources of uncertainty account for $60 \%$ and $47 \%$ of all uncertainties in the NGGIs and FREL reports, respectively. These findings support the assertion by Van der Sluijs [15] that it is necessary to transcend quantitative methods when evaluating highly uncertain phenomena.

Early direct measurements of pan-tropical forest area change involved trade-offs between sensor resolution and completeness of areal coverage [4]. In this study, we found evidence of trade-offs between the completeness of coverage of the six forest carbon fluxes and the disaggregation of estimates between different carbon pools, forest ecosystem types and land covers. This will also constrain REDD+ and Global Stocktake monitoring.

One limitation of this analysis is that the NGGIs and FREL reports were our main source of information. The NGGIs generally lack information on methods and data, and better information provided in the FREL reports suggests that NGGI estimates submitted to the Global Stocktake may be less uncertain than the NGGI estimates evaluated here.

We make three recommendations for future research. First, it would help to undertake empirical tests of the three hypotheses proposed in this paper which link a decline in uncertainty to a rise in the resolution of the three dimensions of Earth observation. Second, the UAF should be applied to compare the uncertainties of government estimates of forest carbon fluxes with those of actual scientific estimates, to better simulate a Global Stocktake comparison of estimates in NGGIs and scientific estimates synthesized by the IPCC. Third, it is important to study social and economic constraints on the adoption of state-of-the-art Earth observation technologies by tropical countries. We have included preliminary assessments of the operational feasibility of these technologies, but a more systematic feasibility assessment method is required.

Two changes in global climate change policy are recommended. First, a second phase of REDD+ Readiness schemes is needed to help tropical countries to reduce uncertainties about the magnitudes 
of forest degradation and forest (re)growth, by undertaking more frequent national forest carbon inventories that integrate ground measurements and Earth observation. Second, the UNFCCC should reduce terminological difficulties by clearly defining the terms "forest degradation", "Forest Reference Emission Level" and "Forest Reference Level".

Supplementary Materials: The following are available online at http://www.mdpi.com/2072-4292/12/15/2369/s1, Supplementary Material. Supplementary Tables S1-S14. Supplementary Figures S1-S3.

Author Contributions: A.G. designed the study, carried out research and wrote the paper. J.K. contributed to the research. All authors have read and agreed to the published version of the manuscript.

Funding: This research received no external funding.

Acknowledgments: This paper was inspired by discussions at a workshop on REDD+ MRV Centres held on 23 May 2018 at the School of Geography, Geology and the Environment at the University of Leicester. The workshop was convened in association with the National Centre for Earth Observation and the Department for Business, Energy and Industrial Strategy. Particular thanks are due to Heiko Balzter (University of Leicester) and Joanne Nightingale (National Physical Laboratory) for helping to organize the workshop and for commenting on an early draft of this paper.

Conflicts of Interest: The authors declare no conflict of interest.

\section{References}

1. UNFCCC. Adoption of the Paris Agreement; Report of the Conference of the Parties; 21st session; Paris; 30 November to 11 December 2015; Agenda item 4(b); FCCC/CP/2015/L.9/Rev.1; UN Framework Convention on Climate Change: Bonn, Germany, 2015.

2. UNFCCC. Key Decisions Relevant for Reducing Emissions from Deforestation and Forest Degradation in Developing Countries (REDD+); Decision Booklet REDD+ (Includes the Warsaw Framework for REDD+); UN Framework Convention on Climate Change: Bonn, Germany, 2014.

3. La Queré, C.; Andres, R.J.; Boden, T.; Conway, T.; Houghton, R.A.; House, J.I.; Marland, G.; Peters, G.P.; Van der Werf, G.; Ahlström, A. The global carbon budget 1959-2011. Earth Syst. Sci. Data 2013, 5, $165-185$. [CrossRef]

4. Grainger, A. Uncertainty in constructing global knowledge about tropical forests. Prog. Phys. Geogr. 2010, 34, 811-844. [CrossRef]

5. Goward, S.N. Land remote sensing in the 21st Century: Geotechnologies in service to human societies. Geofocus 2007, 7, 1-4.

6. Townshend, J.R.; Masek, J.G.; Huang, C.; Vermote, E.F.; Gao, F.; Channan, S.; Sexton, J.O.; Feng, M.; Narasimhan, R.; Kim, D.; et al. Global characterization and monitoring of forest cover using Landsat data, opportunities and challenges. Int. J. Digit. Earth 2012, 5, 373-397. [CrossRef]

7. Baccini, A.; Walker, W.; Carvalho, L.; Farina, M.; Sulla-Menashe, D.; Houghton, R.A. Tropical forests are a net carbon source based on aboveground measurements of gain and loss. Science 2017, 358, 230-234. [CrossRef]

8. Lachowski, H.M.; Dietrich, D.L. Forest Inventory of the Philippines Using Satellite Imagery; General Electric Company: Beltsville, MD, USA, 1978.

9. Morain, S.A.; Klankamsorn, B. Forest mapping and inventory techniques through visual analysis of Landsat imagery-Examples from Thailand. In Proceedings of the International Symposium on Remote Sensing of Environment, Ann Arbor, MI, USA, 20-26 April 1978; pp. 417-426.

10. Hardcastle, P.D.; Baird, D.; Harden, V.; Abbott, P.G.; O’Hara, P.; Palmer, J.R.; Roby, A.; Haüsler, T.; Ambia, V.; Branthomme, A.; et al. Capability and Cost Assessment of the Major Forest Nations to Measure and Monitor Their Forest Carbon; LTS International: Edinburgh, Scotland, 2008.

11. Pelletier, J.; Ramankutty, N.; Potvin, C. Diagnosing the uncertainty and detectability of emission reductions for REDD + under current capabilities, an example for Panama. Environ. Res. Lett. 2011, 6, 024005. [CrossRef]

12. Mertz, O.; Grogan, K.; Pflugmacher, D.; Lestrelin, G.; Castella, J.-C.; Vongvisouk, T.; Hett, C.; Fensholt, R.; Sun, Z.; Berry, N.; et al. Uncertainty in establishing forest reference levels and predicting future forest-based carbon stocks for REDD+. J. Land Use Sci. 2018, 13, 1-15. [CrossRef]

13. Baker, D.J.; Richards, G.; Grainger, A.; Brown, S.; DeFries, R.; Gonzalez, P.; Held, A.; Kellndorfer, J.; Ndunda, P.; Ojima, D.; et al. Achieving forest carbon information with higher certainty, a five step strategy. Environ. Sci. Policy 2010, 13, 249-260. [CrossRef] 
14. Minang, P.A.; Van Noordwijk, M.; Duguma, L.A.; Alemagi, D.; Do, H.T.; Bernard, F.; Agung, P.; Robiglio, V.; Catacutan, D.; Sutanto, S.; et al. REDD+ Readiness progress across countries, time for reconsideration. Clim. Policy 2014, 14, 685-708. [CrossRef]

15. Van Der Sluijs, J.P. Anchoring Amid Uncertainty: On the Management of Uncertainties in Risk Assessment of Anthropogenic Climate Change. Ph.D. Thesis, Utrecht University, Utrecht, The Netherlands, 1997.

16. Achache, J. From GMES to NOE: A European network for the management of the environment. Space Policy 2001, 17, 97-101. [CrossRef]

17. Grainger, A. Citizen observatories and the new Earth observation science. Remote Sens. 2017, 9, 153. [CrossRef]

18. Tucker, C.J.; Townshend, J.R.G. Strategies for monitoring tropical deforestation using satellite data. Int. J. Remote Sens. 2000, 21, 1461-1471. [CrossRef]

19. Lippitt, C.D.; Stow, D.A. Remote sensing theory and time-sensitive information. In Time-Sensitive Remote Sensing; Lippitt, C.D., Stow, D.A., Clarke, K.C., Eds.; Springer: Berlin/Heidelberg, Germany, 2015; pp. 1-10.

20. Grainger, A. Are Global Environmental Uncertainties Inevitable? School of Geography, University of Leeds: Leeds, UK, 2020.

21. FAO. Global Forest Resources Assessment 2010; FAO Forestry Paper No. 163; UN Food and Agriculture Organization: Rome, Italy, 2010.

22. FAO. Tropical Forest Resources; FAO Forestry Paper No. 30; UN Food and Agriculture Organization: Rome, Italy, 1982.

23. Grainger, A. The degradation of tropical rain forest in Southeast Asia, taxonomy and appraisal. In Land Degradation in the Tropics; Eden, M.E., Parry, J.T., Eds.; Mansell: London, UK, 1996; pp. 61-75.

24. Grainger, A. The forest transition, an alternative approach. Area 1995, 27, 242-251.

25. Wiersum, K.F. Introduction, towards a global forestation strategy. In Proceedings of the an International Symposium on Strategies and Designs for Afforestation, Reforestation and Tree Planting, Wageningen, The Netherlands, 19-23 September 1983; Wiersum, K.F., Ed.; Pudoc: Wageningen, The Netherlands, 1984; pp. 7-25.

26. Brienen, R.J.W.; Phillips, O.L.; Feldpausch, T.R.; Gloor, E.; Baker, T.R.; Lloyd, J.; Lopez-Gonzalez, G.; Monteagudo-Mendoza, A.; Malhi, Y.; Lewis, S.L.; et al. Long-term decline of the Amazon carbon sink. Nature 2015, 519, 344-348. [CrossRef] [PubMed]

27. UNFCCC. UNFCCC Resource Guide for Preparing the National Communications of Non-Annex 1 Parties. Module 3, National Greenhouse Gas Inventories; UN Framework Convention on Climate Change: Bonn, Germany, 2009.

28. UNFCCC. Report of the Conference of the Parties, 24th session, Katowice, 2 to 15 December 2018. Part Two, Action taken by the Conference of the Parties at its twenty fourth session; FCCC/CP/2018/10/Add.1; UN Framework Convention on Climate Change: Bonn, Germany, 2019.

29. Watson, R.T.; Noble, I.R.; Bolin, B.; Ravindranath, N.H.; Verardo, D.J.; Dokken, D.J. Land Use, Land-Use Change and Forestry; IPCC/Cambridge University Press: Cambridge, UK, 2000.

30. Grainger, A. Modelling the impact of alternative afforestation strategies to reduce carbon emissions. In Proceedings of the IPCC Conference on Tropical Forestry Response Options to Global Climate Change, São Paulo, Brazil, 9-11 January 1990; Report No. 20P-2003. Office of Policy Analysis, US Environmental Protection Agency: Washington, DC, USA, 1990; pp. 93-104.

31. IPCC. First Assessment Report, Working Group III, The IPCC Response Strategies; Intergovernmental Panel on Climate Change, World Meteorological Organisation, UN Environment Programme: Geneva, Switzerland, 1990; pp. 97-102.

32. UNFCCC. Report of the Conference of the Parties, 13th session, Bali, 3 to 15 December 2007. Part Two, Action taken by the Conference of the Parties at its thirteenth session; FCCC/CP/2007/6/Add.1; UN Framework Convention on Climate Change: Bonn, Germany, 2007.

33. UNFCCC. Report of the Conference of the Parties, 11th session, Montreal, 28 November to 10 December 2005. Part One, Proceedings; FCCC/CP/2005/5; UN Framework Convention on Climate Change: Bonn, Germany, 2005.

34. UNFCCC. Report of the Conference of the Parties, 15th Session, Copenhagen, 7 to 19 December 2009. Part Two, Action Taken by the Conference of the Parties at Its Fifteenth Session; FCCC/CP/2009/11/Add.1; UN Framework Convention on Climate Change: Bonn, Germany, 2010.

35. Whittaker, R.H. Communities and Ecosystems; Collier Macmillan: New York, NY, USA, 1972. 
36. Whittaker, R.H.; Likens, G.E. Primary production, the biosphere and man. Hum. Ecol. 1973, 1, $357-369$. [CrossRef]

37. IPCC. 2006 IPCC Guidelines for National Greenhouse Gas Inventories. Volume 4. Agriculture, Forestry and Other Land Use; Eggleston, S., Buendia, L., Miwa, K., Ngara, T., Tanabe, K., Eds.; Intergovernmental Panel on Climate Change, National Greenhouse Gas Inventories Programme, Technical Support Unit; Institute for Global Environmental Strategies: Hayama, Japan, 2006.

38. FAO. Global Forest Resources Assessment 2000; FAO Forestry Paper No. 140; UN Food and Agriculture Organization: Rome, Italy, 2001.

39. Eyre, S.R. Vegetation and Soils. A World Picture; Edward Arnold: London, UK, 1963.

40. UNFCCC. Report of the Conference of the Parties, 7th session, Marrakesh, 29 October to 10 November 2001. Part Two, Action taken by the Conference of the Parties at Its Seventh Session; UN Framework Convention on Climate Change: Bonn, Germany, 2001.

41. Schulze, E.-D.; Valentini, R.; Sanz, M.-J. The long way from Kyoto to Marrakesh: Implications of the Kyoto Protocol negotiations for global ecology. Glob. Chang. Biol. 2002, 8, 505-518. [CrossRef]

42. Lund, H.G. Definitions of Forest, Deforestation, Afforestation and Reforestation; Forest Information Services: Manassas, VA, USA, 1999.

43. UNFCCC. Report of the Conference of the Parties, 17th session, Durban, 28 November to 9 December 2011. Decision 17/CP.8, FCCC/CP/2011/9/Add.1; UN Framework Convention on Climate Change: Bonn, Germany, 2011.

44. IPCC. IPCC Good Practice Guidance for Land Use, Land Use Change and Forestry; Penman, J., Gytarsky, M., Hiraishi, T., Krug, T., Kruger, D., Pipatti, R., Buendia, L., Miwa, K., Ngara, T., Tanabe, K., et al., Eds.; Intergovernmental Panel on Climate Change, National Greenhouse Gas Inventories Programme, Technical Support Unit; Institute for Global Environmental Strategies: Hayama. Japan, 2003.

45. UN. UN Framework Convention on Climate Change; United Nations: New York, NY, USA, 1992.

46. Böschen, S.; Kastenhofer, K.; Rust, I.; Soentgen, J.; Wehling, P. Scientific nonknowledge and its political dynamics. Sci. Technol. Hum. Values 2010, 35, 783-811. [CrossRef]

47. Wynne, B. Uncertainty and environmental learning. Reconceiving science and policy in the preventive paradigm. Glob. Environ. Chang. 1992, 2, 111-127. [CrossRef]

48. Funtowicz, S.O.; Ravetz, J.R. Uncertainty and Quality in Science for Policy; Kluwer: Dordrecht, The Netherlands, 1990.

49. Regan, H.M.; Colyman, M.; Burgman, M.A. A taxonomy and treatment of uncertainty for ecology and conservation biology. Ecol. Appl. 2002, 12, 618-628. [CrossRef]

50. Van Asselt, M.B.A.; Rotmans, J. Uncertainty in integrated assessment modelling. Clim. Chang. 2002, 54, 75-105. [CrossRef]

51. Aamodt, A.; Nygard, M. Different roles and mutual dependencies of data, information and knowledge-An AI perspective on their integration. Data Knowl. Eng. 1995, 16, 191-222. [CrossRef]

52. Lillesand, T.M.; Kiefer, R.W.; Chipman, J. Remote Sensing and Image Interpretation; John Wiley: Chichester, UK, 2008.

53. Keenan, R.J.; Reams, G.A.; Achard, F.; De Freitas, J.; Grainger, A.; Lindquist, E. Dynamics of global forest area, results from FAO Global Forest Resources Assessment 2015. For. Ecol. Manag. 2015, 352, 9-20. [CrossRef]

54. Government of Brazil. Third National Communication of Brazil to the UNFCCC; Ministry of Science, Technology and Innovation: Brasilia, Brazil, 2016; Volume 3.

55. Government of Cambodia. Second National Communication of Cambodia to the UNFCCC; Department of Climate Change: Phnom Penh, Cambodia, 2015.

56. Government of the Democratic Republic of the Congo. Third National Communication to the UNFCCC; Ministry of Environment, Nature Conservation and Tourism: Kinshasa, Democratic Republic of the Congo, 2015.

57. Government of Costa Rica. Third National Communication of Costa Rica to the UNFCCC; Ministry of Environment and Energy: San Jose, Costa Rica, 2014.

58. Government of Ghana. Third National Communication of Ghana to the UNFCCC; Environmental Protection Agency: Accra, Ghana, 2015.

59. Government of Indonesia. Second National Communication of Indonesia to the UNFCCC; Republic of Indonesia Ministry of Environment: Jakarta, Indonesia, 2011.

60. Government of Laos. Second National Communication to the UNFCCC; Prime Minister's Office: Vientiane, Laos, 2013.

61. Government of Malaysia. Third National Communication to the UNFCCC; Ministry of Natural Resources and Environment and Forestry: Kuala Lumpur, Malaysia, 2018. 
62. Government of Mexico. Fifth National Communication to the UNFCCC; Comision Intersecretarial de Cambio Climático: Mexico City, Mexico, 2012.

63. Government of Nigeria. Second National Communication to the UNFCCC; Federal Ministry of the Environment: Abuja, Nigeria, 2014.

64. Government of Peru. Third National Communication to the UNFCCC; Ministry of the Environment: Lima, Peru, 2016.

65. Government of United Republic of Tanzania. Second National Communication to the UNFCCC; Vice-President's Office: Dar Es Salaam, Tanzania, 2014.

66. Government of Brazil. Brazil's Submission of a Forest Reference Emission Level (FREL) for Reducing Emissions from Deforestation in the Amazonia Biome for REDD+Results-Based Payments under the UNFCCC from 2016 to 2020; Ministry of Science, Technology and Innovation: Brasilia, Brazil, 2018.

67. Government of Cambodia. Forest Reference Level; Department of Climate Change: Phnom Penh, Cambodia, 2017.

68. Government of Democratic Republic of the Congo. Niveau D'emissions de Reference des Forets pour la Reduction des Emissions dues a la Deforestation en Republic Democratique du Congo; Ministry of Environment, Nature Conservation and Tourism: Kinshasa, Democratic Republic of Congo, 2018.

69. Government of Costa Rica. Modified REDD+ Forest Reference Emission Level/Forest Reference Level (FREL/FRL); Ministry of Environment and Energy: San Jose, Costa Rica, 2016.

70. Government of Ghana. Ghana's National Forest Reference Level; National REDD+ Secretariat, Forestry Commission: Accra, Ghana, 2017.

71. Government of Indonesia. National Forest Reference Level Level for Deforestation and Forest Degradation; Ministry of Environment and Forestry: Jakarta, Indonesia, 2017.

72. Government of Laos. Forest Reference Emission Level and Forest Reference Level for REDD+Results-Based Payment under the UNFCCC; Department of Forestry, Ministry of Agriculture and Forestry: Vientiane, Laos, 2018.

73. Government of Malaysia. Malaysia's Submission on Reference Levels for REDD+Results-Based Payments under UNFCCC; Ministry of Natural Resources and Environment: Kuala Lumpur, Malaysia, 2018.

74. Government of Mexico. National Forest Reference Emission Level Proposal Mexico; Secretariat of Environment and Natural Resources: Mexico City, Mexico, 2015.

75. Government of Nigeria. National Forest Reference Emission Level (FREL) for the Federal Republic of Nigeria; Federal Department of Forestry and Federal Ministry of Environment: Abuja, Nigeria, 2019.

76. Government of Peru. Peru's Submission of a Forest Reference Emission Level (FREL) for Reducing Emissions from Deforestation in the Peruvian Amazon; Ministry of the Environment: Lima, Peru, 2016.

77. Government of United Republic of Tanzania. Tanzania's Forest Reference Emission Level Submission to the UNFCCC; Vice-President's Office: Dar Es Salaam, United Republic of Tanzania, 2017.

78. IPCC. Definitions and Methodological Options to Inventory Emissions from Direct Human-Induced Degradation; Penman, J., Gytarsky, M., Hiraishi, T., Krug, T., Kruger, D., Pipatti, R., Buendia, L., Miwa, K., Ngara, T., Tanabe, K., et al., Eds.; Intergovernmental Panel on Climate Change and Institute for Global Environmental Strategies: Kanagawa, Japan, 2003.

79. Grainger, A. Difficulties in tracking the long-term global trend in tropical forest area. Proc. Natl. Acad. Sci. USA 2008, 105, 818-823. [CrossRef]

80. Lanly, J.P. (Ed.) Tropical Forest Resources Assessment Project (GEMS), Tropical Africa, Tropical Asia, Tropical America; UN Food and Agriculture Organization/ UN Environment Programme: Rome, Italy, 1981.

81. FAO. Forest Resources Assessment 1990, Tropical Countries; FAO Forestry Paper No. 112; UN Food and Agriculture Organization: Rome, Italy, 1993.

82. FAO. Global Forest Resources Assessment 2005; FAO Forestry Paper No. 147; UN Food and Agriculture Organization: Rome, Italy, 2006.

83. Hansen, M.C.; Stehman, S.V.; Potapov, P.V.; Loveland, T.R.; Townshend, J.R.G.; DeFries, R.S.; Pittman, K.W.; Arunarwati, B.; Stolle, F.; Steininger, M.K.; et al. Humid tropical forest clearing from 2000 to 2005 quantified by using multitemporal and multiresolution remotely sensed data. Proc. Natl. Acad. Sci. USA 2008, 105, 9439-9444. [CrossRef] [PubMed]

84. Asner, G.P.; Knapp, D.E.; Broadbent, E.N.; Oliveira, P.J.C.; Keller, M.; Silva, J.N. Selective logging in the Brazilian Amazon. Science 2005, 310, 480-482. [CrossRef]

85. De Souza, C.M., Jr.; Roberts, D.A.; Cochrane, M.A. Combining spectral and spatial information to map canopy damage from selective logging and forest fires. Remote Sens. Environ. 2005, 98, 329-343. [CrossRef] 
86. Hirschmugl, M.; Steinegger, M.; Gallaun, H.; Schardt, M. Mapping forest degradation due to selective logging by means of time series analysis, case studies in central Africa. Remote Sens. 2014, 6, 756-774. [CrossRef]

87. Shimabukuro, Y.E.; Beuchle, R.; Grecchi, R.; Frédéric, A. Assessment of forest degradation in Brazilian Amazon due to selective logging and fires using time series of fraction images derived from Landsat ETM+ images. Remote Sens. Lett. 2014, 5, 773-782. [CrossRef]

88. Ellis, P. Mapping selective logging impacts in Borneo with GPS and airborne lidar. For. Ecol. Manag. 2016, 365, 184-196. [CrossRef]

89. Hansen, M.C.; Potapov, P.V.; Moore, R.; Hancher, M.; Turbanova, S.A.; Tyukavina, S.A.; Thau, D.; Stehman, S.V.; Goetz, S.J.; Loevland, T.R.; et al. High-resolution global maps of 21st-century forest cover change. Science 2013, 342, 850-853. [CrossRef]

90. Bastin, J.-F.; Berrahmouni, N.; Grainger, A.; Maniatis, D.; Mollicone, D.; Moore, R.; Patriarca, C.; Picard, N.; Sparrow, B.; Abraham, E.M.; et al. The extent of forest in dryland biomes. Science 2017, 356, 635-638. [CrossRef] [PubMed]

91. Williams, C.A.; Collatz, G.J.; Masek, J.; Huang, C.; Goward, S.N. Impacts of disturbance history on forest carbon stocks and fluxes, merging satellite disturbance mapping with forest inventory data. Remote Sens. Environ. 2014, 151, 57-71. [CrossRef]

92. Dovers, S.R.; Handmer, J.W. Uncertainty, sustainability and change. Glob. Environ. Chang. 1992, 2, $262-276$. [CrossRef]

93. Handmer, J.W. Ecology, Uncertainty and Policy; Handmer, J.W., Norton, T.R., Dovers, S.R., Eds.; Prentice Hall: Harlow, UK, 2001.

94. Mathieu, P.P.; Desnos, Y.L. Enabling the transition towards Earth Observation Science 2.0. In Proceedings of the EGU General Assembly 2015, Vienna, Austria, 12-17 April 2015.

95. Wagner, W.; Fröhlich, J.; Wotawa, G.; Stowasser, R.; Staudinger, M.; Hoffmann, C.; Walli, A.; Federspiel, C.; Aspetsberger, M.; Atzberger, C.; et al. Addressing grand challenges in Earth observation science: The Earth Observation Data Centre for Water Resources Monitoring. ISPRS Ann. Photogramm. Remote Sens. Spat. Inf. Sci. 2014, II-7, 81-88. [CrossRef]

96. Hermville, L.; Siemons, A.; Förster, H.; Jeffery, L. Catalysing mitigation ambition under the Paris Agreement: Elements for an effective Global Stocktake. Clim. Pol. 2019, 19, 988-1001. [CrossRef] 